\title{
Multiple Pollutants, Uncovered Sectors, and Suboptimal Environmental Policies
}

\author{
Don Fullerton \\ Daniel H. Karney
}

CESIFO WORKING PAPER NO. 4891

CATEGORY 10: ENERGY AND CLIMATE ECONOMICS

JULY 2014

An electronic version of the paper may be downloaded

- from the SSRN website:

- from the RePEc website:

- from the CESifo website:

WwW.SSRN.com

Www.RePEc.org

www.CESifo-group.org/wp

\section{CESifo}




\title{
Multiple Pollutants, Uncovered Sectors, and Suboptimal Environmental Policies
}

\begin{abstract}
In our analytical general equilibrium model where two polluting inputs can be substitutes or complements in production, we study the effects of a tax on one pollutant in two cases: one where both pollutants face taxes and the second where the other pollutant is subject to a permit policy. In each case, we solve for closed-form solutions that highlight important parameters. We demonstrate two important ways that environmental taxes and permits are not equivalent. First, the change in the pollutant facing a tax increase depends on whether the other pollutant is subject to a tax or permit policy. Second, if that other pollutant is subject to a tax, then general equilibrium effects can increase or decrease its quantity (affecting overall welfare). However, when the second pollutant is subject to a permit policy that binds, then welfare is not affected by this spillover effect. Finally, a numerical exercise helps demonstrate these two ways that taxes and permits differ. Using the example of coal-fired power plants, our numerical exercise examines the impacts of increasing a hypothetical carbon tax on the quantity of sulfur dioxide emissions.
\end{abstract}

JEL-Code: H230.

Keywords: general equilibrium, pollution tax, tradable permits, carbon dioxide, sulfur dioxide, climate policy, co-benefits, environmental damages.

\author{
Don Fullerton* \\ University of Illinois \\ Finance Department \\ USA - Champaign IL 61820 \\ dfullert@illinois.edu
}

\author{
Daniel H. Karney \\ University of Illinois \\ Department of Economics \\ USA - Urbana, IL 61801 \\ dkarney2@illinois.edu
}

*corresponding author

We are grateful for suggestions from Stefan Ambec, Kathy Baylis, George Deltas, Firouz Gahvari, Garth Heutel, Stephen Holland, Jonathan Hughes, Ben Marx, Nick Muller, and Ian Sue Wing. 
In a simple model with multiple pollutants, the first-best can be achieved either by a tax on each pollutant or equivalent permit price that reflects each marginal environmental damage. That is, the first-best requires each pollutant to be optimally regulated. Not all pollutants are regulated, however, and even regulated ones likely face suboptimal policy. The multiple pollutant setting creates complications for regulators: tightening rules on one pollutant changes how firms value other pollutants. Thus, a regulator concerned with social welfare who can change only one policy needs to account for changes across multiple pollutants. For example, policymakers who adopt a new carbon policy may not be able to adjust each regulation on other types of pollution, especially where different laws and jurisdictions govern the different pollutants. ${ }^{1}$

Our model is general enough to represent any industry with multiple pollutants that are substitutes or complements, so a price increase on one can induce firms to increase or decrease other pollutants. For example, Sigman (1996) studies chlorinated solvents used for metal cleaning and degreasing, and she finds that raised disposal costs for liquid chemical wastes may lead to more air emissions (i.e., substitutes). ${ }^{2}$ Ren et al. (2011) find that reducing $\mathrm{CO}_{2}$ by use of biofuel can increase nitrogen runoff from farms. Our numerical example below involves coal-fired electric power plants that emit both carbon dioxide $\left(\mathrm{CO}_{2}\right)$ and sulfur dioxide $\left(\mathrm{SO}_{2}\right)$. Agee et al. (2014) describe four ways these two pollutants could be substitutes or complements. ${ }^{3}$ They "find that reducing $\mathrm{NO}_{\mathrm{X}}$ has substantially reduced $\mathrm{SO}_{2}$ and $\mathrm{CO}_{2}$, while reducing $\mathrm{SO}_{2}$ has substantially increased $\mathrm{CO}_{2}$ ” (p.66). Our illustration uses the U.S. EPA assumption that a carbon tax reduces use of coal and therefore both pollutants (i.e., complements).

A permit policy limits $\mathrm{SO}_{2}$ from power plants under the U.S. Acid Rain Program (ARP), which has received much academic attention. ${ }^{4}$ If $\mathrm{CO}_{2}$ were to be regulated by a

\footnotetext{
${ }^{1}$ In fact, studies of a particular environmental regulation often include "ancillary" benefits from the reduction of other pollutants. See Burtraw et al. (2003), Groosman et al. (2011) and Kolstad et al. (2014).

${ }^{2}$ Yet, Greenstone (2003) finds little evidence that the Clean Air Act increased water or ground pollution. Gamper-Rabindran (2006) finds that off-site recycling is a substitute for chemical waste disposal, while Färe et al. (2012) find that $\mathrm{NO}_{\mathrm{X}}$ and $\mathrm{SO}_{2}$ are substitutes in production at power plants.

${ }^{3}$ In response to $\mathrm{SO}_{2}$ controls, the switch to low-sulfur coal with lower heat rate could increase $\mathrm{CO}_{2}$ per kilowatt hour. Also, desulfurization equipment uses electric power that requires burning more coal and may generate added $\mathrm{CO}_{2}$ emissions from the chemical reactions that capture $\mathrm{SO}_{2}$. If the response is to shut down dirty plants, then effects on $\mathrm{CO}_{2}$ depend on whether new plants use coal or natural gas.

${ }^{4}$ See Schmalensee et al. (1998), Burtraw et al. (1998), and Carlson et al. (2000). The ARP's cap on $\mathrm{SO}_{2}$ is not currently binding, so the permit price is zero (starting in 2011). To explore the general problem of interactions between pollution policies, our numerical exercises use positive $\mathrm{SO}_{2}$ prices from 2007 data.
} 
tax, then we expect a reduction in carbon emissions, but $\mathrm{SO}_{2}$ permit prices may rise or fall depending on the degree to which carbon and sulfur are complements in production.

While some of the features of our model have appeared in prior literature, our paper is the first to combine all four of the following. First, we model analytically the general case where two pollutants can be complements or substitutes in production. ${ }^{5}$

Second, not all pollutants are necessarily controlled by the same type of environmental policy. Indeed, one pollutant might be subject to a tax, while another is limited under a permit system. Therefore, we use a framework that can analyze multiple combinations of tax and permit policies. We show how doing so allows for a relatively easy comparison of policy scenarios available to regulators. ${ }^{6}$

Third, environmental policies are likely to be suboptimal, where the marginal price per unit of pollution does not equal the marginal environmental damage. In a multiple pollutant setting, each policy regulating each pollutant is unlikely to be optimal for at least three reasons: technical limitations and informational constraints may preclude correct estimation of social costs and benefits; political concerns may prevent the adoption of a first-best policy; and, a pollution tax or price likely reflects conditions at the time of enactment rather than present or future conditions. Furthermore, multiple pollutants - even from a single source - are not necessarily all regulated by a single regulator using a comprehensive approach. Thus, we address situations where a regulator must choose a policy given existing regulations on other pollutants. ${ }^{7}$

Fourth, a pollution tax or permit system is unlikely to cover all sectors. A carbon policy such as a tax or cap-and-trade system may cover more than just power plants, but it cannot cover all carbon emissions from all industrial, commercial, transportation, and residential sources. Existing estimates suggest that carbon policy can apply at most to

\footnotetext{
${ }^{5}$ For examples of other models with multiple pollutants that could be complements or substitutes in production, see Moslener and Requate (2007), Holland (2012b), Ren et al. (2011), and Agee et al. (2014).

${ }^{6}$ Ambec and Coria (2013) provide a recent theoretical contribution that simultaneously analyzes a mix of tax and permit policies, using a "prices vs. quantities" approach in the style of Weitzman (1974) for the case with a technological externality for abatement effort. The sign of their key technology parameter determines whether the pollutants are substitutes or complements. Our paper differs by using a general equilibrium approach with perfect certainty, and we do not solve for either first- or second-best results. Ambec and Coria (2013) rank the welfare outcomes of policy mixes, while we focus on the general equilibrium effects for a wide range of policy choices and settings.

${ }^{7}$ Moslener and Requate (2007) derive optimal abatement strategies in a dynamic multi-pollutant model. We limit our analysis to welfare effects of small changes from a suboptimal equilibrium, because many studies already consider first-best and second-best optimal policy with other distortions.
} 
approximately 80 percent of U.S. carbon emissions (Metcalf and Weisbach, 2009). If so, then a rise in the carbon price or tax may have multiple second-best effects, as carbon emissions shift to uncovered sectors (i.e. carbon leakage). ${ }^{8}$

Our analytical model has two sectors and two pollutants, where initial policy is suboptimal. Both sectors are competitive, with constant returns to scale production. We employ standard assumptions that include full information, factor mobility, and certainty, but a less standard assumption is that one sector has three inputs: two kinds of pollution and a clean input. We refer to the clean input as labor, but it could represent labor, capital, or a composite of all clean inputs. For concreteness, our primary example is electricity generation that uses labor, $\mathrm{SO}_{2}$ and $\mathrm{CO}_{2}$. With three inputs to production in the covered sector that faces an increased carbon tax, the elasticities of substitution between inputs become key model parameters. In addition, we assume that the other, uncovered sector employs two inputs, labor and carbon, where these carbon emissions face an unchanged price. Log-linearization allows us to evaluate policy changes.

Each pollutant in the covered sector could face a tax or permit policy, so we analyze four potential combinations. Our example for the tax-permit scenario is a tax on carbon with a permit policy on sulfur. We solve explicitly for the tax-tax and taxpermit scenarios, but the model is symmetric so the permit-tax and permit-permit scenarios are analogous. In these scenarios, we hold the sulfur policy constant and solve for effects of a small increase in the carbon tax. We find closed-form solutions, interpret them, and decompose them into output and substitution effects.

The tax-tax scenario provides important baseline results. Our simple closedform solutions characterize the conditions that guarantee particular outcomes (although perverse signs on outcomes can occur with extreme parameter values). In particular, the signs of elasticities of substitution are important. When the carbon tax is raised, holding the sulfur tax constant, then the covered sector's output falls (except in unusual cases identified below). When the two pollutants are substitutes, then $\mathrm{SO}_{2}$ may rise or fall, but when they are complements then both effects act to reduce sulfur emissions with positive effects on welfare.

The tax-permit results are more complicated than the tax-tax results, because the

\footnotetext{
${ }^{8}$ Baylis et al. (2014) analyze and discuss the carbon leakage issue in greater detail. In addition, Holland (2012a) and Karp (2013) provide recent, analytical models of carbon leakage.
} 
covered sector essentially has a fixed factor of production. Specifically, the closedform solutions in this scenario have a denominator with an ambiguous sign, unlike those in the tax-tax scenario. However, we show how to use the tax-tax scenario solutions to interpret both the numerator and denominator of the tax-permit solutions.

The results from the tax-tax and tax-permit scenarios highlight two important ways that environmental tax and permits differ in a model with perfect certainty. First, given a tax increase on one pollutant, its quantity change depends on whether the other pollutant is subject to a tax or a permit policy. At coal-fired power plants, for example, carbon abatement resulting from a 10 percent increase in carbon tax depends on whether $\mathrm{SO}_{2}$ faces a tax or permit policy. Second, if $\mathrm{SO}_{2}$ were subject to a tax, then its quantity can increase or decrease in a way that impacts overall welfare gains from the carbon tax increase itself. However, when the second pollutant is subject to a permit policy and that policy binds, then welfare does not change via spillover effects.

Our numerical exercise using historical data from 2007 helps demonstrate the two ways that taxes and permits differ in this paper. In the tax-tax scenario, a 10 percent increase in a carbon tax is found to decrease $\mathrm{CO}_{2}$ emissions by 4.6 percent, and to decrease $\mathrm{SO}_{2}$ by 0.9 percent. However, the same 10 percent carbon tax increase in the tax-permit scenario results in a smaller decrease in $\mathrm{CO}_{2}$ emissions and zero change in the quantity of $\mathrm{SO}_{2}$ (by definition). Despite the same tax increase in both scenarios, these differences in outcomes yield welfare gains in the tax-tax scenario that are more than twice the gains in the tax-permit scenario.

Section 1 below presents our basic model with multiple pollutants, and section 2 outlines our welfare analysis. Section 3 provides closed-form, analytical solutions for changes in endogenous variables, given exogenous changes in policy. Section 4 identifies plausible parameter values to calibrate the model. Section 5 uses those values for numerical results, and it conducts sensitivity analysis. Section 6 briefly concludes.

\section{Model}

We assume perfect competition, full information, mobile factors, many identical agents, lump-sum transfers, costless enforcement of policies, and perfect mixing of pollutants (i.e. no non-convexities or "hot-spots"). While both sectors face a positive price for carbon emissions from various existing energy policies, we model effects of a tighter 
carbon policy in a "covered" sector that does not apply to the uncovered sector. We compare only long-run equilibria and do not consider adjustment costs.

\section{A Initial Setup}

The covered sector produces output $Y$ by a constant return to scale (CRTS) production function $Y=Y\left(L_{Y}, C_{Y}, S\right)$, where $L_{Y}$ is a productive resource called labor that could be a composite of all non-polluting factors (labor, capital, land, and technology). The representative firm pays a market-clearing price $\left(p_{L}\right)$ for the composite labor input, and it emits both carbon $\left(C_{Y}\right)$ and sulfur $(S) .{ }^{9}$ In sector $Y$, carbon and sulfur each face a tax or permit price, depending on prevailing regulation, so the firm pays a price $p_{C Y}$ when emitting carbon and $p_{S}$ when emitting sulfur. The government returns all revenue from taxes or permit sales via lump-sum transfer to the representative household.

Good $X$ is the other good, produced in the uncovered sector, which emits only carbon $\left(C_{X}\right)$. Good $X$ is produced by the CRTS production function $X=X\left(L_{X}, C_{X}\right)$, where $L_{X}$ denotes labor use. ${ }^{10}$ Labor is undifferentiated, so the representative firm in sector $X$ also pays $p_{L}$ per unit of labor. This sector does not face an explicit carbon policy, but it does face an implicit price of carbon $\left(p_{C X}\right)$ from other policies such as a gasoline tax, BTU tax, or fuel-efficiency standards.

The binding resource constraint in this economy is given by $L \equiv L_{Y}+L_{X}$. Here, a fixed total amount of labor is perfectly mobile between sectors $X$ and $Y$, so leisure does not enter the utility function. In both sectors, all inputs are necessary for production and exhibit diminishing marginal returns. These conditions - along with regularity conditions on the consumer side - guarantee an interior solution.

In a generic utility function $U=U(X, Y ; C, S)$, the representative household gets positive utility from the consumption of goods $X$ and $Y$, and receives disutility from total carbon emissions $C=C_{Y}+C_{X}$ and from sulfur emissions $S$. The household can choose its level of $X$ and $Y$, but not $C$ or $S$, where pollutants are separable. ${ }^{11}$

\footnotetext{
${ }^{9}$ Pollutant $S$ could be a generic "smoke" pollutant that accounts for all non-carbon pollution. Also, since firms are identical, trades are irrelevant, and the permit system is equivalent to non-tradable quotas.

${ }^{10}$ As a special case, the production of good $X$ could be perfectly clean, emitting no pollution $\left(C_{X}=0\right)$ and eliminating the leakage component of the model.

${ }^{11}$ Many simplifying assumptions here would be interesting to investigate in a more complex model. With non-separability in utility, for example, changes in pollution can further affect demands. With
} 
Also, $p_{X}$ is the market clearing price for good $X$, and $p_{Y}$ is the analogous price for good $Y$. The household maximization problem is:

$$
\max _{\{X, Y\}} U(X, Y ; C, S) \quad \text { s.t. } \quad p_{L} L+R \geq p_{X} X+p_{Y} Y
$$

where $R$ is the lump sum rebate of revenue from the government, viewed as fixed by the consumer but calculated as $R \equiv p_{C Y} C_{Y}+p_{S} S+p_{C X} C_{X}$.

\section{B Log-Linearization}

Totally differentiate the resource constraint $L \equiv L_{Y}+L_{X}$ to get:

$$
0=\alpha_{X} \hat{L}_{X}+\alpha_{Y} \hat{L}_{Y}
$$

where $\alpha_{X} \equiv L_{X} / L$ is the share of labor in production of good $X$ and $\alpha_{Y} \equiv L_{Y} / L$ is the share of labor used in $Y$. Note that $\alpha_{X}+\alpha_{Y}=1$. We use the "hat" notation throughout this paper to denote a proportional change in any variable (e.g. $\hat{L}_{X} \equiv d L_{X} / L_{X}$ ).

Totally differentiate the production functions to show how final output changes when firms adjust input quantities:

$$
\begin{aligned}
& \hat{X}=\theta_{X L} \hat{L}_{X}+\theta_{X C} \hat{C}_{X} \\
& \hat{Y}=\theta_{Y L} \hat{L}_{Y}+\theta_{Y C} \hat{C}_{Y}+\theta_{Y S} \hat{S}
\end{aligned}
$$

where $\theta_{g i}$ is the factor share of income for input $i$ in the production of good $g$ (e.g. $\left.\theta_{X L} \equiv p_{L} L_{X} / p_{X} X\right)$. Thus, $\theta_{X L}+\theta_{X C}=1$ and $\theta_{Y L}+\theta_{Y C}+\theta_{Y S}=1$.

The zero profit conditions due to perfect competition are $p_{X} X=p_{L} L_{X}+p_{C X} C_{X}$ and $p_{Y} Y=p_{L} L_{Y}+p_{C Y} C_{Y}+p_{S} S$. Totally differentiate these equations and use the profit maximizing first-order conditions:

$$
\begin{aligned}
& \hat{p}_{X}+\hat{X}=\theta_{X L}\left(\hat{p}_{L}+\hat{L}_{X}\right)+\theta_{X C}\left(\hat{p}_{C X}+\hat{C}_{X}\right) \\
& \hat{p}_{Y}+\hat{Y}=\theta_{Y L}\left(\hat{p}_{L}+\hat{L}_{Y}\right)+\theta_{Y C}\left(\hat{p}_{C Y}+\hat{C}_{Y}\right)+\theta_{Y S}\left(\hat{p}_{S}+\hat{S}\right) .
\end{aligned}
$$

consumer heterogeneity, policies would have distributional effects. With firm heterogeneity, tradable permits would be more efficient than firm-specific quotas. With locational heterogeneity, different sources would have differential damages (e.g. Muller and Mendelsohn (2009)). All of these interesting extensions are beyond the scope of the present paper, but are investigated elsewhere. 
Good $X$ has only two inputs, so factor use responds to changes in relative input prices via the elasticity of substitution, $\sigma_{X}$. Differentiating the definition of $\sigma_{X}$ yields:

$$
\hat{C}_{X}-\hat{L}_{X}=\sigma_{X}\left(\hat{p}_{L}-\hat{p}_{C X}\right)
$$

To handle three inputs to $Y$, we follow Allen (1938), as in Mieszkowski (1972). ${ }^{12}$ Define $e_{i j}$ as the Allen-elasticity of substitution between input $i$ and input $j$. That is, $e_{i j}$ measures the effect on the quantity of $i$ from a change in the price of input $j$, holding all other input prices constant. As shown in Appendix A, the relative input factor responses in sector $Y$ are given by:

$$
\begin{aligned}
& \hat{L}_{Y}-\hat{S}=\left(e_{L L}-e_{S L}\right) \theta_{Y L} \hat{p}_{L}+\left(e_{L C}-e_{S C}\right) \theta_{Y C} \hat{p}_{C Y}+\left(e_{L S}-e_{S S}\right) \theta_{Y S} \hat{p}_{S} \\
& \hat{C}_{Y}-\hat{S}=\left(e_{C L}-e_{S L}\right) \theta_{Y L} \hat{p}_{L}+\left(e_{C C}-e_{S C}\right) \theta_{Y C} \hat{p}_{C Y}+\left(e_{C S}-e_{S S}\right) \theta_{Y S} \hat{p}_{S} .
\end{aligned}
$$

If $e_{i j}$ is positive, then the inputs are substitutes; if it is negative, they are complements. Each input is a complement to itself $\left(e_{i i} \leq 0, \forall i\right)$. The Allen-elasticities are symmetric, $e_{i j}=e_{j i}$, and at most one of the three cross-price elasticities can be negative. ${ }^{13}$

Finally, since pollution is separable in utility, we use $\sigma_{U}$ for the elasticity of substitution in utility between $X$ and $Y$. Differentiation yields changes in demand behavior from a shift in output prices:

$$
\hat{X}-\hat{Y}=\sigma_{U}\left(\hat{p}_{Y}-\hat{p}_{X}\right) .
$$

These nine linear equation are solved below for the equilibrium impacts of $\hat{p}_{C Y}$, a small change in the covered sector's price of carbon. ${ }^{14}$

\section{Welfare Changes}

Regulators in a multiple pollutant setting have the additional concern that changing regulation on one pollutant has general equilibrium effects that can change the quantity

\footnotetext{
${ }^{12}$ Fullerton and Heutel (2007) similarly model relationships among labor, capital, and a single pollutant.

13 A profit maximizing firm conforms to $a_{i L}+a_{i C}+a_{i S}=0$, where $a_{i j}$ is the partial elasticity of substitution in production (related to the Allen-elasticity of substitution by $a_{i j}=\theta_{Y j} e_{i j}$ ).

14 These equations cannot exactly consider the introduction of a new carbon tax, because the initial $p_{C Y}$ cannot be zero in the denominator of $\hat{p}_{C Y}=d p_{C Y} / p_{C Y}$. The initial tax could be very small, however.
} 
of other pollutants. In fact, tightening regulation on one pollutant may increase pollution in uncovered sectors and increase emissions of the other pollutant, both results that decrease welfare (due to initially suboptimal regulation).

Define $\mu_{C}$ as the marginal environmental damage (MED) from a unit of carbon, and define $\mu_{S}$ as the MED from a unit of sulfur. In other words, $\mu_{C} \equiv-(\partial U / \partial C) / \lambda$, and $\mu_{S} \equiv-(\partial U / \partial S) / \lambda$, where $\lambda$ is the marginal utility of income. In general, the welfare change - derived in Appendix B - is given by:

$$
\frac{d U}{\lambda I}=\left(p_{C X}-\mu_{C}\right) \frac{C_{X}}{I} \hat{C}_{X}+\left(p_{C Y}-\mu_{C}\right) \frac{C_{Y}}{I} \hat{C}_{Y}+\left(p_{S}-\mu_{S}\right) \frac{S}{I} \hat{S}
$$

The left-hand side is the dollar value of the change in utility $(d U / \lambda)$, divided by national income $(I)$. Thus, it represents the percentage change in welfare (as in Bovenberg and de Mooij, 1994, or Fullerton and Metcalf, 2001).

Consider the case where carbon is initially under-priced relative to its MED, such that $p_{C X}<p_{C Y}<\mu_{C}$. Suppose all pollutants face environmental taxes, but policymakers increase the carbon tax in $Y\left(\hat{p}_{C Y}>0\right)$, holding other taxes constant $\left(\hat{p}_{S}=\hat{p}_{C X}=0\right)$. Any reduction in $C_{Y}$ then raises welfare through the second term above. Yet this tax on carbon may have negative effects on welfare through either of the other two terms, because the covered sector may increase use of sulfur $(\hat{S}>0)$, and the uncovered sector may increase use of carbon $\left(\hat{C}_{X}>0\right)$. Thus, welfare is generally ambiguous.

Next, consider the case where carbon in $Y$ is subject to a tax increase, but sulfur is controlled by a permit policy ( $\hat{S}=0$, where the permit policy binds). Thus, only carbon leakage to the uncovered sector can offset welfare gains from reductions in $C_{Y}$. If $p_{Y C}$ is "near" the MED, then the welfare gain from $\hat{C}_{Y}<0$ can be offset by the welfare loss from leakage $\left(\hat{C}_{X}>0\right)$. Again, to evaluate final welfare changes would require values for parameters in the closed-form solutions derived in the next section. ${ }^{15}$

\footnotetext{
${ }^{15}$ Our simple model assumes perfect mixing, so a binding sulfur permit policy means no effect on welfare from any change in sulfur. More generally, of course, the policy may not be binding, and the carbon tax may change sulfur emissions. Even with binding sulfur permits, but without perfect mixing, the added carbon tax may cause a re-allocation of sulfur from low- to high-damage locations.
} 


\section{Analytical Solutions for a Change in Carbon Policy}

Equations (1) - (9) are the linear system for general equilibrium effects of a small policy change. We define $L$ as numeraire, so $\hat{p}_{L}=0$, and we hold the carbon price in sector $X$ constant relative to that numeraire (as is necessary for the regulatory change not to apply to the uncovered sector). Thus $\hat{p}_{C X}=0$, so equation (6) simplifies to $\hat{C}_{X}=\hat{L}_{X}$. Next, simplify equation (4) and compare it to equation (2) to show that $\hat{p}_{X}=0$. Good $X$ acts as an equivalent numeraire, because both of its inputs have unchanged prices. Equation (4) becomes redundant to equation (2), leaving eight equations.

The two pollutants in sector $Y$ are regulated, where either $C_{Y}$ or $S$ can face an environmental tax or permit policy. In a tax-tax scenario, the carbon tax exogenously increases $\left(\hat{p}_{C Y}>0\right)$, while the sulfur tax remains constant $\left(\hat{p}_{S}=0\right)$, leaving the carbon quantity $\left(\hat{C}_{Y}\right)$ and sulfur quantity $(\hat{S})$ to vary endogenously. In contrast, a tax-permit scenario means that the carbon tax increases, but the sulfur quantity remains unchanged $(\hat{S}=0)$, allowing the carbon quantity $\left(\hat{C}_{Y}\right)$ and sulfur price $\left(\hat{p}_{S}\right)$ to adjust. Thus, among the four potential policy variables in the set $\left\{\hat{p}_{C Y}, \hat{C}_{Y}, \hat{p}_{S}, \hat{S}\right\}$, two will be specified as exogenous changes, while the other two remain endogenous. The other six unknown variables are $\left\{\hat{X}, \hat{L}_{X}, \hat{C}_{X}, \hat{Y}, \hat{L}_{Y}, \hat{p}_{Y}\right\}$, so each policy scenario yields a linear system with eight equations and eight unknowns.

Table 1 categorizes four possible scenarios, given two pollutants and two policy regimes for each pollutant. However, we explicitly solve and analyze only two of the four scenarios: the tax-tax case and the tax-permit case (with permits for $S$ ). The model's symmetry means that these two cases implicitly also solve the remaining two scenarios (the permit-tax and permit-permit cases). Thus, for the first column of Table 1 with a sulfur tax, the carbon tax case is functionally equivalent to the box below it with a carbon permit system. ${ }^{16}$ Similarly, for the second column with a sulfur permit system, the effects of a carbon tax are functionally equivalent to the effects of a carbon permit. This symmetry highlights the fact that the type of policy on sulfur fundamentally determines how the covered sector reacts to the tightening restriction on

\footnotetext{
${ }^{16}$ Given a sulfur tax, the case with $1 \%$ higher carbon tax that leads to a $2 \%$ change in carbon is equivalent to the case with a $2 \%$ change in carbon permits (which leads to a $1 \%$ increase in price).
} 
carbon, regardless of whether that carbon restriction is a tax or permit policy. ${ }^{17}$

Table 1: Policy Scenario Matrix, for a Change in Carbon Policy (with $\hat{p}_{C X}=0$ )

\begin{tabular}{|c|c|c|}
\hline & Sulfur Tax & Sulfur Permit \\
\hline $\begin{array}{c}\text { Carbon } \\
\text { Tax }\end{array}$ & $\begin{array}{c}\hat{p}_{C Y}>0 \\
\hat{p}_{S}=0 \\
\text { (Tax-Tax) }\end{array}$ & $\begin{array}{c}\hat{p}_{C Y}>0 \\
\hat{S}=0 \\
\text { (Tax-Permit) }\end{array}$ \\
\hline $\begin{array}{c}\text { Carbon } \\
\text { Permit }\end{array}$ & $\hat{C}_{Y}<0$ & $\hat{C}_{Y}<0$ \\
& $\hat{p}_{S}=0$ & $\hat{S}=0$ \\
(Permit-Tax) & (Permit-Permit) \\
\hline
\end{tabular}

\section{A Tax-Tax Scenario}

The exogenous change in the tax-tax scenario is $\hat{p}_{C Y}>0$. The change in the price of good $Y$ is $\hat{p}_{Y}=\theta_{Y C} \hat{p}_{C Y}$ (by substituting equation (3) into (5) and cancelling terms). Thus, the price of $Y$ always rises relative to the price of $X$ (since $\hat{p}_{X}=0$ ). Further algebra reveals the change in output of good $Y$ (given the sulfur tax, $p_{S}$ ):

$$
\left.\hat{Y}\right|_{p_{S}}=\alpha_{X}\left[\gamma_{C} e_{C C}+\gamma_{S} e_{S C}-\sigma_{U}\right] \theta_{Y C} \hat{p}_{C Y}
$$

where $\gamma_{C} \equiv\left[\frac{\alpha_{Y}}{\alpha_{X}} \frac{\theta_{Y C}}{\theta_{Y L}}\right]>0$ and $\gamma_{S} \equiv\left[\frac{\alpha_{Y}}{\alpha_{X}} \frac{\theta_{Y S}}{\theta_{Y L}}\right]>0$. Perhaps surprisingly, the added carbon tax in $Y$ might raise output. ${ }^{18}$ We interpret the three terms in the brackets in equation (10) when $\hat{p}_{C Y}>0$. First, $\gamma_{C} e_{C C} \leq 0$ reflects an own-price effect on carbon use from an increase in carbon price. All inputs have a positive marginal product, so less carbon means less $Y$. In the third term, when the carbon tax increases $p_{Y}$, then $\sigma_{U}>0$ means that consumers shift demand away from good $Y$. Thus, the sign of $\hat{Y}$ depends on the second term. If the two pollutants are complements $\left(\gamma_{S} e_{S C}<0\right)$, then the higher price of carbon reduces sulfur. Less of this input would also reduce output $Y$,

\footnotetext{
${ }^{17}$ Alternatively, either pollutant could face an environmental mandate. Fullerton and Heutel (2010) show how a restrictions on emissions per unit output is equivalent to the combination of a tax on emissions and subsidy to output. A similar model is possible here but would add considerable complexity.

${ }^{18}$ Output always falls in the simpler model of Baylis et al. (2014), but the carbon tax can raise output in a model with three inputs and particular complementarities (Fullerton and Heutel, 2007).
} 
which then unambiguously falls. This term has the opposite sign when the two pollutants are substitutes, so then the change in $Y$ is ambiguous.

Alternatively, equation (10) can be rewritten as:

$$
\left.\hat{Y}\right|_{p_{S}}=-\left[\alpha_{X} \sigma_{U}+\alpha_{Y} e_{L C}\right] \theta_{Y C} \hat{p}_{C Y}
$$

This equation shows that when carbon and labor are substitutes $\left(e_{L C}>0\right)$, then $Y$ must fall. ${ }^{19}$ We explicitly show those two forms for $\hat{Y}$ because equation (10) highlights the cross-pollutant elasticity $e_{S C}$, while equation (10') provides a more compact closedform solution with fewer parameters.

Next, we solve for the change in the covered sector's carbon emissions: ${ }^{20}$

$$
\left.\hat{C}_{Y}\right|_{p_{S}}=\{\underbrace{-\left(\alpha_{X} \sigma_{U}+\alpha_{Y} e_{L C}\right)}_{\begin{array}{c}
\text { Output } \\
\text { Effect }
\end{array}}+\underbrace{e_{C C}}_{\begin{array}{c}
\text { Substitution } \\
\text { Effect }
\end{array}}\} \theta_{Y C} \hat{p}_{C Y} .
$$

The second term in this equation is the substitution effect. It is always negative, because $e_{C C} \leq 0$; the higher carbon tax induces firms to substitute away from carbon. The first term is called the output effect because it equals $\hat{Y}$ from equation (10'). In general its sign is ambiguous, but only in very unusual cases would a carbon tax increase output in the covered sector. Therefore, $C_{Y}$ likely falls. $^{21}$

Next, we report solutions for the changes in sulfur $(S)$ and labor $\left(L_{Y}\right)$ :

\footnotetext{
${ }^{19}$ This $e_{L C}>0$ does not imply $e_{S C}<0$, but $e_{S C}<0$ does imply $e_{L C}>0$ (since the properties of Allenelasticities guarantee $0=\theta_{Y L} e_{L C}+\theta_{Y C} e_{C C}+\theta_{Y S} e_{S C}$ and $\left.e_{C C}<0\right)$. Therefore, to guarantee $\hat{Y}<0$, carbon and labor being substitutes is a more general condition than the pollutants being complements. Also, it might be easier to determine empirically whether $C$ and $L$ are substitutes, since $L$ is often well measured.

${ }^{20}$ Equation (11) can be inverted to yield the solution to the permit-tax scenario (where carbon gets a tighter permit policy, while sulfur is subject to a tax): $\left.\hat{p}_{C Y}\right|_{p_{S}}=\left\{\frac{1}{-\left(\alpha_{X} \sigma_{U}+\alpha_{Y} e_{L C}\right)+e_{C C}}\right\}\left[\frac{\hat{C}_{Y}}{\theta_{Y C}}\right]$.

${ }^{21}$ From (10'), output $Y$ rises when $C_{Y}$ and $L_{Y}$ are complements $\left(e_{L C}<0\right)$ and $\left|\alpha_{Y} e_{L C}\right|>\left|\alpha_{X} \sigma_{U}\right|$ ( but from (11), carbon still falls if $\left.\left|e_{C C}\right|>\left|\alpha_{X} \sigma_{U}+\alpha_{Y} e_{L C}\right|\right)$. In our numerical example, $\alpha_{X}$ is much larger than $\alpha_{Y}$ so output of $Y$ always falls. Since $p_{Y} / p_{X}$ rises, $Y$ can only rise if $X$ rises more, which is only possible if real income rises (e.g. if the increase in $p_{C Y}$ reduces distortions from initial $p_{C Y}<p_{C X}$ ).
} 


$$
\begin{aligned}
& \left.\hat{S}\right|_{p_{S}}=\left\{-\left(\alpha_{X} \sigma_{U}+\alpha_{Y} e_{L C}\right)+e_{S C}\right\} \theta_{Y C} \hat{p}_{C} \equiv A \hat{p}_{C Y} \\
& \left.\hat{L}_{Y}\right|_{p_{S}}=\left\{-\left(\alpha_{X} \sigma_{U}+\alpha_{Y} e_{L C}\right)+e_{L C}\right\} \theta_{Y C} \hat{p}_{C Y}
\end{aligned}
$$

where the notation $A \hat{p}_{C Y}$ in (12) is used below. Equations (12) and (13) have forms similar to (11). The output effect is the same in all three equations (and it is negative except in unusual cases, as discussed). The substitution effect in (11) has a clear sign (because $e_{C C}<0$ ), but the substitution effects in equations (12) and (13) have ambiguous signs (since the signs of $e_{S C}$ and $e_{L C}$ are ambiguous). For instance, if the two pollutants are substitutes $\left(e_{S C}>0\right)$, then the carbon tax has a positive substitution effect on sulfur. Since the output effect is usually negative, however, the net effect on sulfur would still be ambiguous. However, if the two pollutants are complements (as in EPA assumptions used below), then the carbon tax would reduce sulfur in both terms.

The change in labor is similarly ambiguous. Only one of the three cross-price Allen-elasticities can be negative, however, so both $e_{S C}$ and $e_{L C}$ cannot simultaneously have negative signs. Thus, one of those substitution effects is positive. Furthermore, we can rewrite (13) as:

$$
\left.\hat{L}_{Y}\right|_{p_{S}}=-\alpha_{X}\left[\sigma_{U}-e_{L C}\right] \theta_{Y C} \hat{p}_{C Y} .
$$

Therefore, $\sigma_{U}>e_{L C}$ guarantees $\hat{L}_{Y}<0$ (because consumers substitute away from $Y$ ). Since $\sigma_{U}>0$, equation (13') says that $L_{Y}$ must fall, unless labor and carbon are more substitutable in production than the two goods are substitutable in utility.

Finally, we look at carbon leakage, defined as the change in pollution in the other sector, building on Baylis et al. (2014). They have a simpler model, with carbon as the only pollutant, and they show that because firms in sector $X$ face an unchanged cost of carbon $\left(\hat{p}_{C X}=0\right)$ with labor as numeraire $\left(\hat{p}_{L}=0\right)$, they choose to adjust carbon and labor inputs equally $\left(\hat{C}_{X}=\hat{L}_{X}\right)$. With CRTS, proportional changes in both inputs means the same proportional change in output, and leakage here is: 


$$
\left.\hat{C}_{X}\right|_{p_{S}}=\left.\hat{L}_{X}\right|_{p_{S}}=\left.\hat{X}\right|_{p_{S}}=-\left(\alpha_{Y} / \alpha_{X}\right) \hat{L}_{Y}=\alpha_{Y}\left[\sigma_{U}-e_{L C}\right] \theta_{Y C} \hat{p}_{C Y} .
$$

In summary, these closed-form solutions highlight how the signs of endogenous outcomes are determined by cross-price elasticities that need to be estimated. We show how an increase in the carbon tax decreases carbon emissions in the covered sector (except in unusual cases where covered sector output rises). The same carbon tax may or may not raise sulfur emissions when the pollutants are substitutes, but it reduces $\mathrm{SO}_{2}$ when the pollutants are complements (except in unusual cases with more output). The amount of labor used in the covered sector falls, unless labor and carbon are more substitutable in production than the goods are substitutable in consumption.

\section{B Tax-Permit Scenario}

If a tax is levied on carbon while sulfur is subject to a permit policy, then $\hat{p}_{C Y}>0$ and $\hat{S}=0$. Here, the quantity of sulfur is fixed, so changes in the carbon tax do not affect sulfur emissions. Unlike the tax-tax scenario, the price change in sector $Y$ can have an ambiguous sign and is recursively given by $\hat{p}_{Y}=\theta_{Y S} \hat{p}_{S}+\theta_{Y C} \hat{p}_{C Y}$, where $\hat{p}_{S}$ is now endogenous. Also, unlike the tax-tax scenario, price changes such as $\hat{p}_{S}$ in the taxpermit scenario include a denominator $(D)$. To define this term $D$, we first digress to look briefly at an alternate tax-tax case with a change only in the sulfur tax:

$$
\left.\hat{S}\right|_{p_{C Y}}=\left\{-\left(\alpha_{X} \sigma_{U}+\alpha_{Y} e_{L S}\right)+e_{S S}\right\} \theta_{Y S} \hat{p}_{S} \equiv D \hat{p}_{S} .
$$

This equation merely switches the roles of $C_{Y}$ and $S$ in equation (11) above (instead of finding the effect on carbon from a change in carbon tax, it show the effect on sulfur from a change in the sulfur tax). The reason for that digression is that we can use it to show the effect on sulfur price from a change in carbon tax:

$$
\left.\hat{p}_{S}\right|_{S}=-\left[\frac{-\left(\alpha_{X} \sigma_{U}+\alpha_{Y} e_{L C}\right)+e_{S C}}{-\left(\alpha_{X} \sigma_{U}+\alpha_{Y} e_{L S}\right)+e_{S S}}\right] \frac{\theta_{Y C}}{\theta_{Y S}} \hat{p}_{C Y}=-\frac{A}{D} \hat{p}_{C Y}
$$

where $A$ is the coefficient from equation (12) in the tax-tax scenario. 
The change in sulfur permit price has an ambiguous sign, and equation (16) initially appears complicated relative to solutions in the tax-tax scenario, because it contains four different Allen-elasticites and a denominator. While $D$ is not necessarily negative, a strong enough substitution effect in equation (15) would likely mean that an increase in the sulfur tax decreases the sulfur quantity (in that other tax-tax scenario). Closed-form solutions for the other endogenous variables in the tax-permit scenario have the same denominator as equation (16), so for purposes of discussion we focus on the "normal" case where $e_{S S}<0$ is large enough to ensure that $D$ is negative.

In the numerator $(A)$ of the tax-permit scenario in (16), suppose carbon and sulfur are complements (where $e_{S C}<0$ implies $e_{L C}>0$ and $e_{L S}>0$ ). Intuitively, when the pollutants are complements, an increase in carbon price reduces demand for sulfur and thus the sulfur price. Furthermore, neither $e_{L C}>0$ nor $e_{L S}>0$ guarantees $\hat{p}_{S}<0$, so the sign of the cross-price elasticity between pollutants provides greater information on the sign of endogenous variables than does the sign of the cross-price elasticity between labor and either pollutant (where the opposite is true in the tax-tax scenario).

Next, solving the closed-form solution for $\hat{p}_{Y}$ yields:

$$
\left.\hat{p}_{Y}\right|_{S}=\frac{\theta_{Y C} D-\theta_{Y S} A}{D} \hat{p}_{C Y}
$$

where the denominator is the same as in equation (16), and the sign is generally ambiguous. The output price may fall despite an increase in the cost of an input. A large enough substitution effect in $D$ leads to $\left(\theta_{Y C} D-\theta_{Y S} A\right)<0$, however, meaning the price of good $Y$ likely increases (since we assume the denominator is likely negative).

Recursively, the change in output is $\hat{Y}=\theta_{Y L} \hat{L}_{Y}+\theta_{Y C} \hat{C}_{Y}$, which is simply the weighted-sum of the changes in the two inputs (since the tax-permit scenario fixes the quantity of sulfur). Solving for the closed-form solution yields:

$$
\left.\hat{Y}\right|_{S}=-\frac{e_{S C} \theta_{Y C} D-e_{S S} \theta_{Y S} A}{D} \hat{p}_{C Y}
$$

where (18) looks similar to (17), but Allen elasticities enter each numerator term to switch from a price solution to a quantity solution. Also, equation (18) has a negative sign, unlike (17), because price and quantity generally move in opposite directions. 
Next, insert $\hat{S}=0$ into (3) and solve for $\hat{C}_{Y}=\frac{1}{\theta_{Y C}}\left[\hat{Y}-\theta_{Y L} \hat{L}_{Y}\right]$, an expression that decomposes the change in carbon into output and substitution effects. Here, due to the fixed sulfur content, the substitution effect is just the scaled change in the clean labor input. The closed-form solution is:

$$
\left.\hat{C}_{Y}\right|_{S}=-\frac{\left(e_{S C}-e_{C C}\right) \theta_{Y C} D-\left(e_{S S}-e_{C S}\right) \theta_{Y S} A}{D} \hat{p}_{C Y} .
$$

This equation is similar to (18), but it has two more elasticities in the numerator. Again, we might expect the quantity of carbon to fall when the carbon tax increases, but equation (19) in general has an ambiguous sign. However, the two pairs of elasticity parameters in the numerator can help explain the ambiguity. The pair $\left(e_{S C}-e_{C C}\right)$ measures the relative changes in sulfur and carbon given a carbon price change. Most plausible parameters suggest that the own-price effect is larger than cross-price effects. Thus, since $e_{C C}<0$, and assuming that $\left|e_{C C}\right|>\left|e_{S C}\right|$, then $\left(e_{S C}-e_{C C}\right)>0$ means the first term in the numerator is negative (reducing carbon in $Y$ ). ${ }^{22}$

Finally, comparing equations (11) and (19) shows that whether sulfur faces a tax or permit policy clearly changes how the carbon tax affects the quantity of carbon emissions. When the increased carbon tax affects sulfur quantities, only in the tax-tax case, pollutant complementarity means that those changes in sulfur quantities have their own feedback effects on the desired quantity of carbon input.

Similarly, the change in the clean composite (labor and capital) input $L_{Y}$ in the tax-permit scenario can be decomposed into output and substitution effects using equation (3) with $\hat{S}=0$. The closed-form solution here is also complicated, given by:

$$
\left.\hat{L}_{Y}\right|_{S}=-\frac{\left(e_{S C}-e_{L C}\right) \theta_{Y C} D-\left(e_{S S}-e_{L S}\right) \theta_{Y S} A}{D} \hat{p}_{C Y} .
$$

It has a form like equation (19), but with some of the elasticity parameters switched. Specifically, $\left(e_{S C}-e_{L C}\right)$ measures the relative changes in sulfur and labor given a carbon price change, while $\left(e_{S S}-e_{L S}\right)$ measures the relative change in sulfur and labor

\footnotetext{
${ }^{22}$ Similarly, the pair $\left(e_{S S}-e_{C S}\right)$ measures the relative changes in sulfur and carbon, given the sulfur price change from equation (16) and recalling the symmetry of Allen-elasticities $\left(e_{S C}=e_{C S}\right)$.
} 
given a sulfur price change. Finally, as in the tax-tax scenario, carbon leakage in sector

$X$ is given by the recursive equation $\hat{C}_{X}=-\left(\alpha_{Y} / \alpha_{X}\right) \hat{L}_{Y}$.

Overall, compared to the tax-tax scenario, we find that the tax-permit scenario has more ambiguous outcomes that depend on parameter values, since sector $Y$ has a fixed-factor of production $(S)$. As in the tax-tax scenario, however, we can still

decompose the changes to input variables $\left(\hat{C}_{Y}\right.$ and $\left.\hat{L}_{Y}\right)$, into output and substitution effects. In the end, we still highlight the intermediate conclusion that the cross-price elasticities need to be estimated.

\section{Parameter Values}

This section provides parameter values for a numerical illustration that uses equations above to solve for endogenous outcomes and welfare. Analytical expressions in section 3 are complex, with ambiguous signs in many instances, so this calculation can help determine both signs and magnitudes. The covered sector in this example is all of U.S. electricity generation, which emits both $\mathrm{CO}_{2}$ and $\mathrm{SO}_{2}$ and which can substitute away from carbon in the long run by switching from coal to natural gas or wind power.

We note that the price of sulfur permits has recently fallen to zero in the U.S., but we wish to illustrate our model for positive pollution prices, so we calibrate the model to emission data and economic data from the year 2007. Also, our simplified analytical model does not capture all possible effects of a carbon tax in general equilibrium, such as in a computational model with explicit fuel markets. It is therefore not a "forecast" of actual effects from a carbon tax, but merely an illustration of analytical results above.

\section{A Benchmark Levels}

The U.S. National Income and Product Accounts (NIPA) report 2007 GDP of \$13,808 billion, which we use for national income, I (see U.S. BEA, 2009). The U.S. Energy Information Agency (EIA) calculates end-use electricity sales of \$344 billion, or 2.5 percent of total economic activity (U.S. EIA, 2009). Thus, we use $\$ 344$ billion for $p_{Y} Y$. Table 2 records all of the benchmark levels (used to obtain our primary parameters).

Next, the U.S. EPA's Greenhouse Gas Inventory (U.S. EPA, 2009a) reports that electric generators emitted 2,397 million metric tons (MMtons) of $\mathrm{CO}_{2}$ in 2007 (constituting 42 percent of all U.S. domestic $\mathrm{CO}_{2}$ combustion emissions that year). 
While no carbon tax or permit policy currently applies to the U.S. electricity market, we suppose a hypothetical initial price of $\$ 15$ per metric ton of $\mathrm{CO}_{2}$ as a starting point (Hassett, Mathur, and Metcalf, 2009). Thus, $p_{C Y} C_{Y}$ equals $\$ 36$ billion. The rest of the economy emitted 3,339 MMtons of $\mathrm{CO}_{2}$ from fossil fuel combustion in 2007. We use $\$ 5$ per metric ton of $\mathrm{CO}_{2}$ in sector $X$, and thus $p_{C X} C_{X}$ equals $\$ 16.7$ billion. $^{23}$

Table 2: Benchmark Levels

\begin{tabular}{|c|c|c|c|}
\hline Level Variable & Value & Units & Source \\
\hline$C_{Y}$ & $2,397.2$ & MMtons & U.S. EPA (2009a) \\
\hline$p_{C Y}$ & 15.0 & \$/metric ton & $\begin{array}{l}\text { Hassett, Mathur, and } \\
\text { Metcalf (2009) }\end{array}$ \\
\hline$p_{C Y} C_{Y}$ & 36.0 & $\$$ billions & Authors' calculation \\
\hline$S$ & $8,973.0$ & thousand tons & U.S. EPA (2009b) \\
\hline$p_{S}$ & 530.0 & \$/metric ton & Bloomberg Data \\
\hline$p_{S} S$ & 4.8 & $\$$ billions & Authors' calculation \\
\hline$C_{X}$ & $3,338.6$ & MMtons & U.S. EPA (2009a) \\
\hline$p_{C X}$ & 5.0 & $\$ /$ metric ton & Authors' assumption \\
\hline$p_{C X} C_{X}$ & 16.7 & $\$$ billions & Authors' calculation \\
\hline$I=\mathrm{GDP}$ & $13,807.5$ & \$ billions & U.S. BEA (2009) \\
\hline$p_{Y} Y$ & 343.7 & \$ billions & U.S. EIA (2009) \\
\hline$p_{X} X$ & $13,463.8$ & $\$$ billions & Authors' calculation \\
\hline$R=p_{C Y} C_{Y}+p_{S} S+p_{C X} C_{X}$ & 57.4 & $\$$ billions & Authors' assumption \\
\hline$p_{L} L_{Y}$ & 303.0 & $\$$ billions & Authors' calculation \\
\hline$p_{L} L_{X}$ & $13,447.1$ & $\$$ billions & Authors' calculation \\
\hline$L=L_{X}+L_{Y}$ & $13,750.1$ & $\$$ billions & Authors' calculation \\
\hline
\end{tabular}

Second, the National Emissions Inventory (U.S. EPA, 2009b) reports that generators emitted 8,973 thousand tons of $\mathrm{SO}_{2}$ from fossil fuel combustion in 2007 (constituting 69.4 percent of all U.S. domestic $\mathrm{SO}_{2}$ emissions). For the initial $p_{S}$ in our model, we use the equilibrium price for emission permits under the U.S. EPA's Acid Rain Program cap-and-trade regime, which represents the opportunity cost for each ton

\footnotetext{
${ }^{23}$ Sector $X$ includes all of the economy except electricity. The U.S. gasoline tax as a fraction of those $\mathrm{CO}_{2}$ emissions is over $\$ 5 /$ ton, but it's not clear how much of the gasoline tax covers congestion or other externalities as opposed to carbon. Also, emissions in sector $X$ face other implicit costs from energy efficiency and other regulations. Finally, the Chicago Climate Exchange (CCX) was a market where U.S. companies voluntarily bought and sold carbon allowances, so the price on this exchange represents an opportunity cost that firms faced when emitting $\mathrm{CO}_{2}$. In 2007, the average daily mid price for 2007 allowances was $\$ 3.18$ per metric ton. Rather than attempt a precise calculation, we just use $\$ 5 /$ ton for $p_{C X}$.
} 
of $\mathrm{SO}_{2}$ emissions. We use the average of the 2007 vintage allowance price during the year 2007, or $\$ 530$ per ton of $\mathrm{SO}_{2}$ emissions. Thus, $p_{S} S$ equals $\$ 4.8$ billion. $^{24}$

Since the production function $Y\left(L_{Y}, C_{Y}, S\right)$ exhibits constant returns to scale with zero profits, clean input costs $\left(p_{L} L_{Y}\right)$ can be identified by subtracting the costs of pollution from sales revenue. Then the normalization $p_{L}=1$ determines $L_{Y}$. Since the electricity sector has $\$ 40.8$ billion in emission costs, the remainder of $\$ 303$ billion must be paid to the non-polluting input. A similar calculation is conducted for the rest of the economy to determine $L_{X}$.

Table 3: Primary Parameter Values

\begin{tabular}{|c|c|c|}
\hline Parameter & Value & Source \\
\hline \multicolumn{3}{|c|}{ Panel A: Share Parameters } \\
\hline$\alpha_{X} \equiv L_{X} / L$ & 0.978 & \multirow{2}{*}{ See Table 2} \\
\hline$\alpha_{Y} \equiv L_{Y} / L$ & 0.022 & \\
\hline$\theta_{Y L} \equiv L_{Y} /\left(p_{Y} Y\right)$ & 0.882 & \multirow{3}{*}{ See Table 2} \\
\hline$\theta_{Y C} \equiv\left(p_{C} C_{Y}\right) /\left(p_{Y} Y\right)$ & 0.105 & \\
\hline$\theta_{Y S} \equiv\left(p_{S} S\right) /\left(p_{Y} Y\right)$ & 0.014 & \\
\hline \multicolumn{3}{|c|}{ Panel B: Allen-Elasticities } \\
\hline$e_{S C}$ & -0.6 & Authors' calculation \\
\hline$e_{L S}$ & 0.5 & Considine and Larson (2006) \\
\hline$e_{L C}$ & 0.5 & Authors' assumption \\
\hline$e_{L L}$ & -0.1 & \multirow{3}{*}{ Authors' calculations } \\
\hline$e_{C C}$ & -4.1 & \\
\hline$e_{S S}$ & -27.3 & \\
\hline \multicolumn{3}{|c|}{ Panel C: Other Parameters } \\
\hline$\sigma_{U}$ & 0.25 & Ross (2008) \\
\hline$\mu_{C}$ & 39 & Tol (2009) \\
\hline$\mu_{s}$ & 1,510 & Muller and Mendelsohn (2009) \\
\hline
\end{tabular}

Notes: Values subject to independent rounding.

Next, these levels are converted into the share parameter values used in the loglinearized equations (1)-(9), and hence in the closed-form solutions. For example, Table 3 panel A shows that the U.S. electricity sector uses $2.2 \%$ of the total clean inputs

\footnotetext{
${ }^{24}$ Generating units under $25 \mathrm{MW}$ are exempt from the cap, but a vast majority of emissions are covered. The permit price data are reported by Evolution Markets and retrieved via Bloomberg data terminal.
} 
in the economy $\left(\alpha_{Y}=0.022\right)$, and those clean inputs account for $88.2 \%$ of the inputs in sector $Y\left(\theta_{Y C}=0.882\right)$.

\section{B Allen-Elasticities}

Equations (7)-(8) contain nine Allen-elasticities that determine input demand responses in the covered sector. However, the Allen-elasticities are symmetric $\left(e_{i j}=e_{j i}\right)$. Also, knowing the cross-price Allen-elasticities $\left(e_{i j}\right.$ for $\left.i \neq j\right)$ and share parameters determines the own-price Allen-elasticities (see Appendix A). Thus, we focus on identifying the cross-price Allen-elasticities $\left(e_{S C}, e_{L C}, e_{L S}\right)$, and we use them to determine the ownprice elasticities $\left(e_{L L}, e_{C C}, e_{S S}\right)$. All these are best interpreted as long-run elasticities.

A key question in our analysis is whether the two pollutants are substitutes or complements. As Appendix C explains, we use the EPA's analysis of proposed carbon cap-and-trade law to determine our primary value of $e_{S C}$, and we find -0.6 (so carbon and sulfur are complements under EPA assumptions). Also, we round the 0.47 estimate of Considine and Larson (2006) for the labor and sulfur elasticity to $e_{L S}=0.5$, and we assume that same value for the labor and carbon elasticity $\left(e_{L C}\right)$. Remaining own-price terms are derived from those. Table 3 panel B reports all primary-case elasticity values.

\section{C Other Parameters}

Table 3 panel $\mathrm{C}$ reports the final three parameters needed. For the elasticity of substitution in utility $\left(\sigma_{U}\right)$, we use 0.25 , which is the value used by the U.S. EPA in their computational general equilibrium model as their household substitution parameter between energy and all other goods (Ross, 2008). ${ }^{25}$ Tol (2009) surveys the literature and finds an average estimate for the MED of carbon dioxide $\left(\mu_{C}\right)$ that we convert to \$39 per metric ton for 2007. Muller and Mendelsohn (2009) calculate an average MED of sulfur dioxide $\left(\mu_{S}\right)$ that we convert to $\$ 1,510$ per ton. ${ }^{26}$

\footnotetext{
${ }^{25}$ This low elasticity of substitution in utility between electricity and other goods is consistent with empirical estimates of a low price elasticity of demand for electricity.

${ }^{26}$ Tol (2009) reports a social cost of carbon of $\$ 105$ per metric ton (in 1995), a value we convert to $\mathrm{CO}_{2}$ equivalent and inflate to 2007 dollars using the All Items CPI (Series ID\# CUSR0000SA0). Muller and Mendelsohn (2009) report an $\mathrm{SO}_{2}$ MED estimate in 2002 dollars, which we also inflate to 2007.
} 


\section{$5 \quad$ Numerical Results}

\section{A Results with Primary Parameters}

Our numerical results appear in Table 4. Column (1) reports results for the tax-tax policy scenario, where the carbon tax increases by 10 percent, and an $\mathrm{SO}_{2}$ tax remains constant (so $\hat{p}_{C Y}$ is 0.10 and $\hat{p}_{S}$ is zero by assumption; those entries are shaded grey). As a result of this policy change with primary-case parameters, covered $\mathrm{CO}_{2}$ emissions fall by 4.6 percent, and $\mathrm{SO}_{2}$ emissions fall by almost one percent. As the carbon price increases, complementarity between pollutants $\left(e_{S C}=-0.6\right)$ leads to the decline in $\mathrm{SO}_{2}$ $(-0.90)$. Producers increase their use of the clean input, a result expected from the substitutability between carbon and labor $\left(e_{L C}=0.5\right)$. Next, the price of good $Y$ increases by slightly more than one percent, and output of $Y$ falls by 0.27 percent.

Since production of $X$ retains an unchanged ratio of inputs, the increase in $\hat{L}_{Y}$ means that both $\hat{L}_{X}$ and $\hat{C}_{X}$ must fall. Thus, the tax on $\mathrm{CO}_{2}$ in sector $Y$ cuts carbon in both sectors. Leakage is slightly negative with primary-case parameters. ${ }^{27}$ Carbon pollution can fall in both sectors because carbon has no binding constraint; decreasing its use in one sector does not necessitate increasing its use in the other sector. As a result of the policy change, overall welfare improves by 0.59 percent, which is a utility increase worth $\$ 8.13$ billion per year. The welfare gain is almost evenly split between gains from carbon reduction in the covered sector ( 0.287 percent) and $\mathrm{SO}_{2}$ reductions (0.302 percent). The reduction in carbon emissions of the uncovered sector is small and adds little to welfare. Interesting is the fact that this added carbon tax raises slightly more welfare from $\mathrm{SO}_{2}$ reduction than from $\mathrm{CO}_{2}$ reduction. ${ }^{28}$

However, if both MED’s are really only half of the size measured by Tol (2009) and Muller and Mendelsohn (2009), then the welfare gains fall by more than half (see Table 4 panel C). For example, halving the MEDs for the tax-tax scenario leads to a

\footnotetext{
${ }^{27}$ Intuition for the negative leakage result in Baylis et al. (2014) is simple: a carbon tax can induce firms to use more clean inputs per unit of output, and thus draw resources away from the other sector, which reduces the other sector's output and emissions. The same mechanism operates in this model.

${ }^{28}$ The Muller and Mendelsohn (2009) estimate of marginal damage from sulfur is \$1,310/ton for 2002 (scaled to 2007 in Table 3). But Muller (2014) reports an emission-weighted estimate for the same year that is $\$ 15,906 /$ ton, more than ten times larger. The latter estimate uses different procedures, including a higher value of statistical life (VSL). If we used this latter estimate of $\mu_{S}$, then the huge majority of the welfare gain from a carbon tax increase would be attributable to reductions in sulfur emissions.
} 
welfare gain of 0.123 percent instead of 0.589 percent. Despite the fact that the model's equations for changes are linear, section 3 shows that welfare changes are:

$$
\frac{d U}{\lambda I}=\left(p_{C X}-\mu_{C}\right) \frac{C_{X}}{I} \hat{C}_{X}+\left(p_{C Y}-\mu_{C}\right) \frac{C_{Y}}{I} \hat{C}_{Y}+\left(p_{S}-\mu_{S}\right) \frac{S}{I} \hat{S} .
$$

Table 4: Results with our Primary-case Parameters (\% change)

\begin{tabular}{|c|c|c|c|c|}
\hline \multirow[b]{2}{*}{ Variable/Policy } & \multicolumn{4}{|c|}{ Scenario } \\
\hline & $\begin{array}{c}\text { Tax-Tax } \\
\text { [Baseline] } \\
\text { (1) }\end{array}$ & $\begin{array}{c}\text { Tax-Permit } \\
\text { [Match Tax] } \\
\text { (2) }\end{array}$ & $\begin{array}{l}\text { Tax-Permit } \\
\text { [Match } \\
\text { Carbon] } \\
\text { (3) }\end{array}$ & $\begin{array}{l}\text { Tax-Permit } \\
\text { [Match } \\
\text { Welfare] } \\
\text { (4) }\end{array}$ \\
\hline \multicolumn{5}{|c|}{ Panel A: Quantity and Price Changes } \\
\hline$\hat{C}_{Y}$ & -4.59 & -4.56 & -4.59 & -9.43 \\
\hline$\hat{p}_{C}$ & 10.00 & 10.00 & 10.06 & 20.66 \\
\hline$\hat{S}$ & -0.90 & 0.00 & 0.00 & 0.00 \\
\hline$\hat{p}_{S}$ & 0.00 & -2.35 & -2.36 & -4.85 \\
\hline$\hat{L}_{Y}$ & 0.26 & 0.25 & 0.25 & 0.51 \\
\hline$\hat{p}_{Y}$ & 1.05 & 1.01 & 1.02 & 2.09 \\
\hline$\hat{Y}$ & -0.27 & -0.26 & -0.26 & -0.54 \\
\hline$\hat{X}=\hat{L}_{X}=\hat{C}_{X}$ & -0.006 & -0.006 & -0.006 & -0.012 \\
\hline \multicolumn{5}{|c|}{$\begin{array}{l}\text { Panel B: Welfare Changes [Primary-case] } \\
\text { (MEDs: } \mu_{C}=39.0 \text { and } \mu_{S}=1510 \text { ) }\end{array}$} \\
\hline From $\hat{C}_{Y}$ & 0.287 & 0.285 & 0.287 & 0.589 \\
\hline From $\hat{S}$ & 0.302 & 0.000 & 0.000 & 0.000 \\
\hline From $\hat{C}_{X}$ & 0.0002 & 0.0002 & 0.0002 & 0.0005 \\
\hline Overall \% & 0.589 & 0.285 & 0.287 & 0.589 \\
\hline$\$$ billions & 8.13 & 3.94 & 3.96 & 8.13 \\
\hline \multicolumn{5}{|c|}{$\begin{array}{l}\text { Panel C: Alternate Welfare Changes [Sensitivity Analysis] } \\
\left.\qquad \text { (MEDs: } \mu_{C}=19.5 \text { and } \mu_{S}=755\right)\end{array}$} \\
\hline From $\hat{C}_{Y}$ & 0.054 & 0.053 & 0.054 & 0.110 \\
\hline From $\hat{S}$ & 0.036 & 0.000 & 0.000 & 0.000 \\
\hline From $\hat{C}_{X}$ & 0.0001 & 0.0001 & 0.0001 & 0.0002 \\
\hline Overall \% & 0.123 & 0.053 & 0.054 & $0.110^{\mathrm{a}}$ \\
\hline$\$$ billions & 1.70 & 0.74 & 0.74 & $1.52^{\mathrm{a}}$ \\
\hline
\end{tabular}

Note: Grey cells indicate exogenously set variable. Each cell is independently rounded.

${ }^{a}$ These welfare changes do not match those reported in Column (1). To match the welfare change in this case with the alternate MED values, the carbon tax increase would need to be $23.06 \%$ instead of the 20.66\% reported in Panel A. 
When the MEDs are halved, the differences $\left(p_{C Y}-\mu_{C}\right)$ and $\left(p_{S}-\mu_{S}\right)$ fall by more than half. For example, primary-case parameters values yield $\left(p_{C Y}-\mu_{C}\right)=24$, but halving the carbon MED changes that difference to 4.5, a drop of over 81 percent. Welfare is affected disproportionally by a larger social cost.

Table 4 column (2) reports primary results for the tax-permit scenario with the carbon tax increase of $10 \%$ and holding fixed the permit policy on sulfur. Here, sector $Y$ 's decrease in carbon emissions is only slightly lower than in the tax-tax scenario. However, the welfare gain is only 0.285 percent - approximately half of the gain in the tax-tax scenario - because sulfur is fixed in the tax-permit case. Meanwhile, the sulfur price falls. This column numerically demonstrates how effects of the carbon tax on carbon emissions depend on whether the policy on sulfur is a tax or permit policy.

Table 4 column (3) matches the change in sector $Y$ 's carbon emission across the two policy scenarios. Here, the tax-permit scenario needs a larger carbon tax increase $(10.06 \%)$ to reach the same $4.59 \%$ reduction in carbon emissions as in the tax-tax scenario. ${ }^{29}$ Table 4 column (4) sets the carbon tax increase in tax-permit scenario to match the welfare gains of the tax-tax scenario; we find that this tax rate increase would need to more than double (20.7\% rather than $10 \%){ }^{30}$

Table 5 decomposes the input variables $\left(\hat{C}_{Y}, \hat{S}, \hat{L}_{Y}\right)$ from Table 4 into output and substitution effects, using the analytical expressions in section 4. In column (1), for example, the change in carbon in sector $Y$ is $-4.59 \%$, with -0.27 percentage points coming from the output effect and -4.32 percentage points coming from the substitution effect. The output effect for each cell in Table 5 is just the value of $\hat{Y}$ from the corresponding column in Table 4 (so the output effect is constant within each column). Since the decomposition is linear, the remainder must be the substitution effect.

While the levels of the output and substitution effects are important, we find the ratio of the two effects to be quite informative. First, for $\hat{C}_{Y}$, note that the ratio of the

\footnotetext{
${ }^{29}$ Interestingly, even with a higher tax rate, the tax-permit scenario has a smaller output effect compared to the tax-tax scenario (-0.26\% vs. $-0.27 \%)$. It is offset by a larger substitution effect.

${ }^{30}$ When both pollutants face taxes, a higher carbon tax gets about half of its welfare gain from the $0.9 \%$ sulfur reduction (Table 4 column (1)). Thus, $\mathrm{SO}_{2}$ policy is suboptimal, and we could ask about effects of reducing sulfur directly. From the same benchmark, when we hold the carbon tax constant and suppose that the number of sulfur permits is reduced $0.9 \%$, the effect is almost no reduction in carbon emissions and approximately half the welfare gains of column (1). Alternatively, to match column (1) welfare gain with no change in the carbon tax would require nearly doubling the $\mathrm{SO}_{2}$ cap reduction to -1.74 percent.
} 
substitution effect to the output effect is 16.18 in column (1) but rises to 16.62 in columns (2) - (4). This result is expected, given that the fixed sulfur input in the taxpermit scenarios keeps output from falling as much as in the tax-tax scenario. Second, the ratio for $\hat{C}_{Y}$ is the same in three columns (2) - (4), as expected from the model's linearity. Third, the ratio for $\hat{L}_{Y}$ is the same across all models. Decomposition of output and substitution effect helps to understand the numerical outcomes.

Table 5: Primary-case Output and Substitution Effects (\% change)

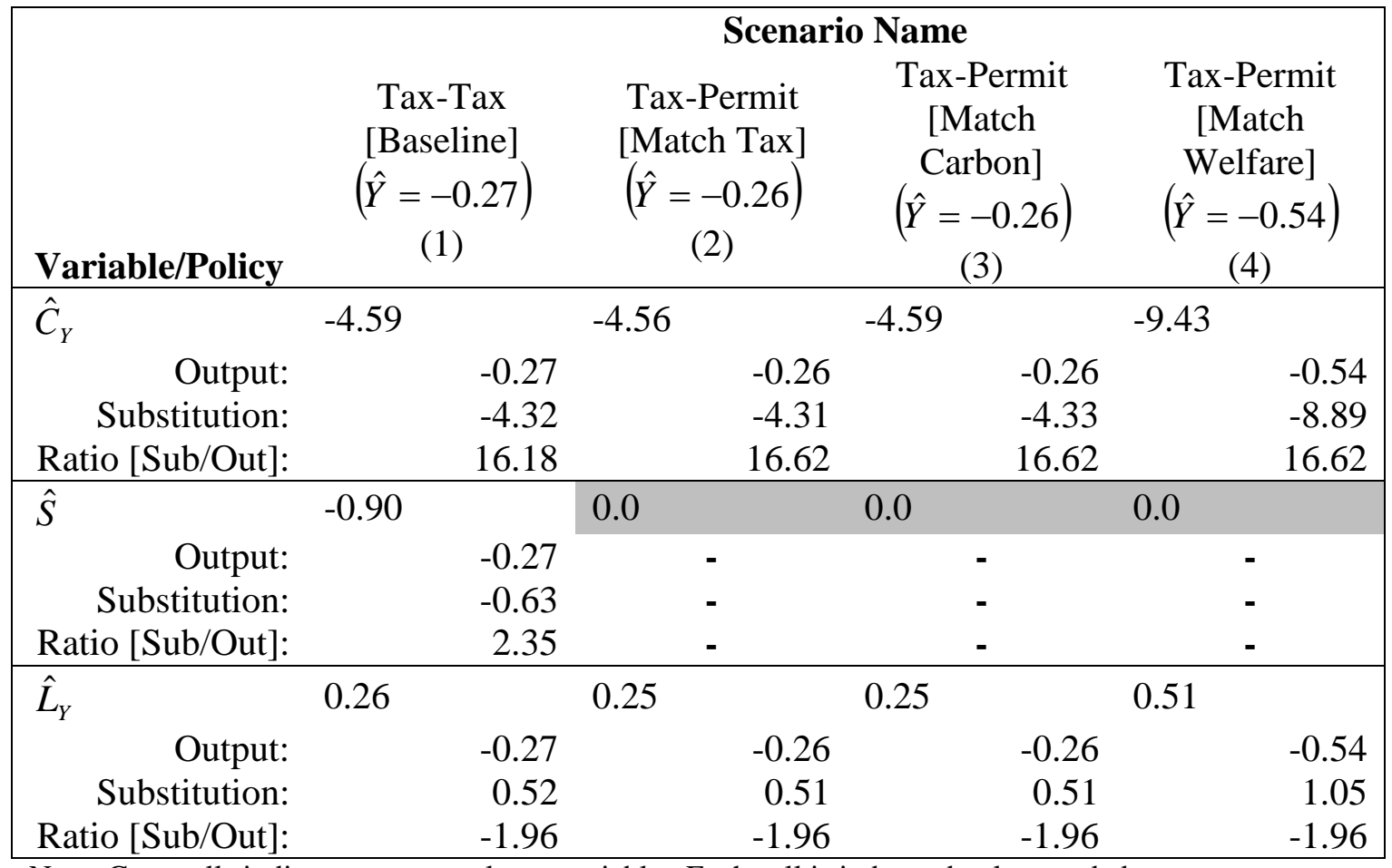

Note: Grey cells indicate exogenously set variable. Each cell is independently rounded.

\section{B Sensitivity}

Whether the two pollutants are substitutes or complements drives many of the empirical results. Thus, we conduct a sensitivity analysis by varying the parameter $e_{S C}$ from -2 to 2 along the horizontal axis in three figures for the tax-tax scenario. When varying $e_{S C}$, we hold the input shares and the other cross-price Allen-elasticities constant (and satisfy $\theta_{Y i} e_{i i}+\theta_{Y j} e_{i j}+\theta_{Y k} e_{i k}=0$ by letting own-price elasticities adjust). In each figure, one curve represents the primary-case assumption of $\sigma_{U}=0.25$, while one curve has no output effect $\left(\sigma_{U}=0\right)$, and the other has a larger output effect $\left(\sigma_{U}=1\right)$. 
Figure 1 shows the percent change in covered carbon dioxide $\left(C_{Y}\right)$ for a 10 percent increase in the carbon tax, while the sulfur tax remains constant. From equation (11), we know that the substitution effect $\left(e_{C C}\right)$ strongly influences this outcome, and thus we observe only small variations in the carbon quantity change for different values of $e_{S C}$ or $\sigma_{U}$. The value of $\hat{C}_{Y}$ on the vertical axis only changes by about one percentage point, such as from -4.0 to -5.0 percent.

\section{Figure 1: Tax-Tax Sensitivity Analysis: Percent Change in Carbon Quantity}

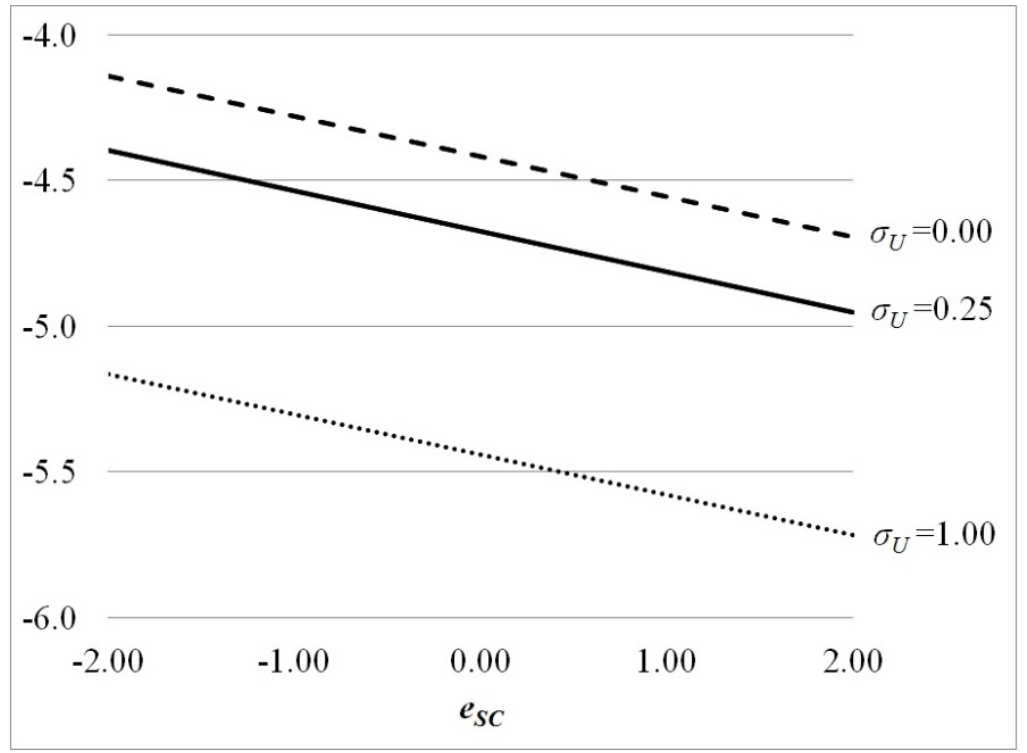

Figure 2: Tax-Tax Sensitivity Analysis: Percent Change in Sulfur Quantity

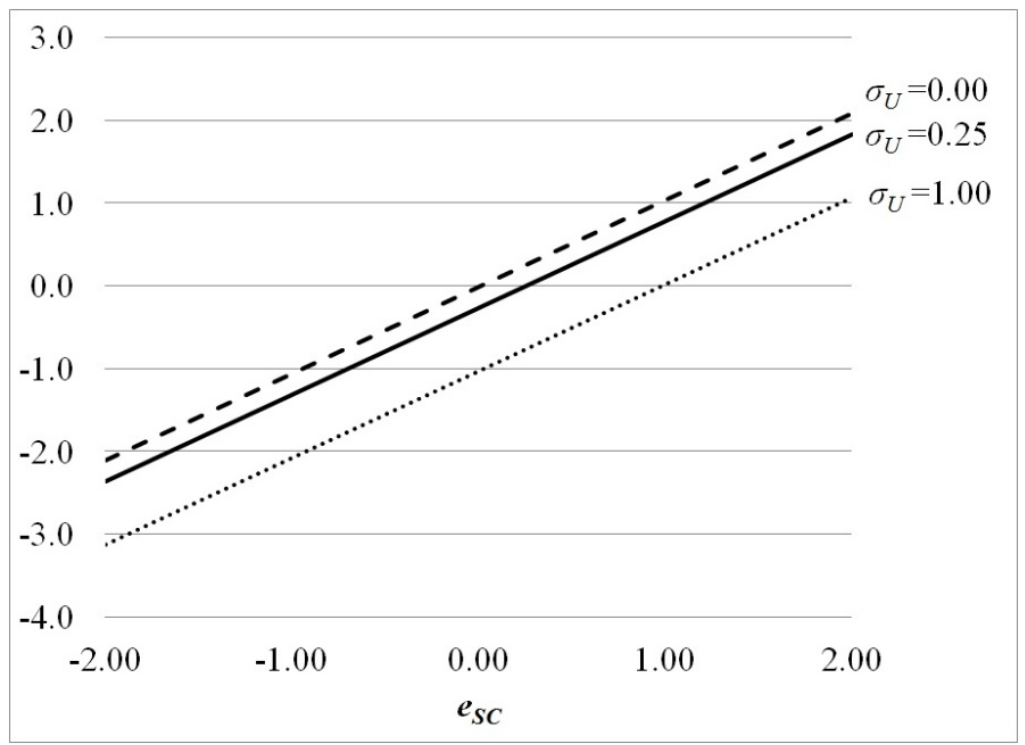


Next, Figure 2 shows that the change $\mathrm{SO}_{2}$ quantity varies greatly across different values of $e_{S C}$. In fact, the sign and size of $\hat{S}$ changes from $-3.0 \%$ to $+2.0 \%$ as the pollutants become strong substitutes. The case with the strong output effect $\left(\sigma_{U}=1\right)$ allows consumers to shift away from good $Y$, which reduces the demand for sulfur.

Lastly, Figure 3 depicts the welfare changes in dollars, and it shows that welfare can indeed fall as a result of tightening carbon policy when the pollutants are highly substitutable. A strong output effect $\left(\sigma_{U}=1\right)$ mitigates that danger to welfare, again because falling output of $Y$ reduces input demand for sulfur emissions. Total benefits can be positive or negative, depending on parameter values.

Figure 3: Tax-Tax Sensitivity: Welfare Change (in billions of dollars)

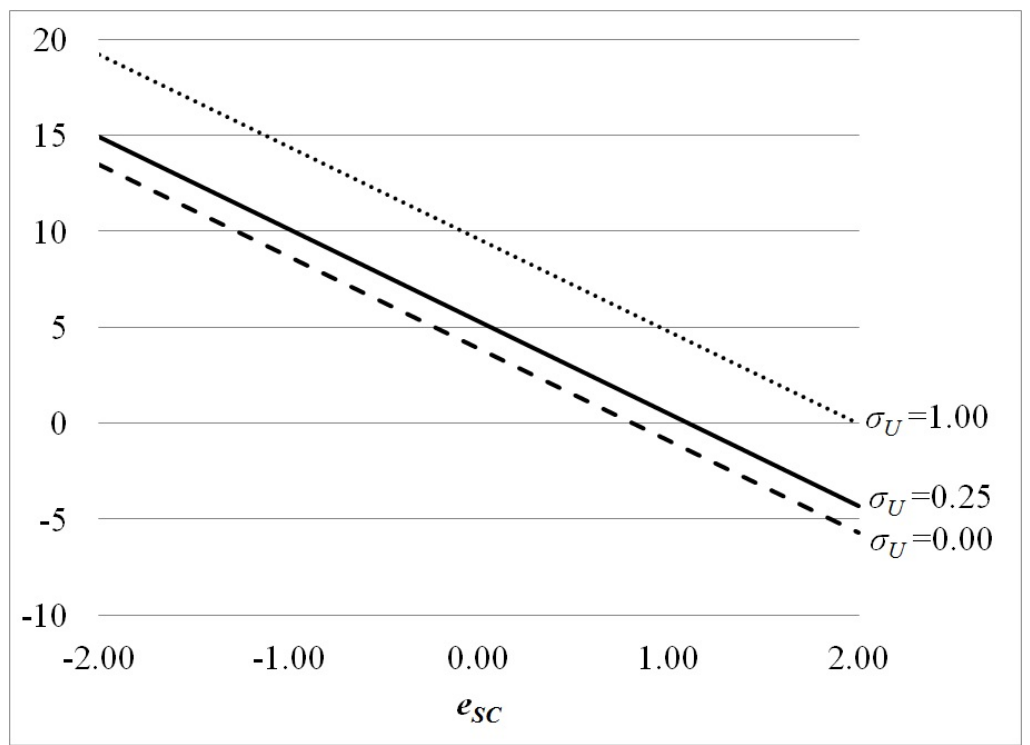

Finally, we observe that the primary-case parameterization leads to some numerical outcomes that do not differ much between the tax-tax and tax-permit scenarios. In the first two columns of Table 4, for example, the output change in sector $Y$ is $-0.27 \%$ in the tax-tax scenario and $-0.26 \%$ in the tax-permit scenario. Similarly, the change in carbon emissions from sector $Y$ is $-4.59 \%$ in the tax-tax scenario and $-4.56 \%$ in the tax-permit scenario. These small numerical differences are due to the small input shares for sulfur and carbon in sector $Y$ (in contrast, note that welfare changes for these two scenarios differ more: $0.589 \%$ vs. $0.285 \%$ ).

Therefore, we conduct sensitivity analysis on these pollution share parameters in Table 6. Column (1) repeats the primary-case from Table 4, while column (2) shows 
results from a numerical example that doubles the sulfur share $\theta_{Y S}$ (from 0.014 to 0.028 , while simultaneously adjusting residual parameters). ${ }^{31}$ Indeed, if $S$ is interpreted as "smoke", to encompass all other pollutants, then the share might well be double that for sulfur alone. For the tax-tax scenario (panel A), $\hat{Y}$ and $\hat{C}_{Y}$ are unaffected by increasing the sulfur share alone, since neither $\theta_{Y S}$ nor any residual parameter appears in equations (10') and (12). Meanwhile, given the same decrease in output, the higher sulfur share means that carbon does not fall as much as in the primary case. For the taxpermit scenario in panel $B$, output and carbon have smaller decreases than in the primary case. The greater sulfur share reduces the input flexibility for sector $Y$, and thus the carbon tax change has less impact. Overall, Table 6 column (2) shows greater differences between the two scenarios when the sulfur share is larger.

Table 6: Share Sensitivity (\% change)

\begin{tabular}{|c|r|r|r|r|}
\hline \multirow{2}{*}{ Variable/Policy } & \multicolumn{4}{|c|}{ Sensitivity } \\
\cline { 2 - 5 } & $\begin{array}{c}\text { Primary-case } \\
(1)\end{array}$ & $\begin{array}{c}\text { Double } \\
\text { Sulfur Share } \\
\left(\theta_{Y S}=0.028\right) \\
(2)\end{array}$ & $\begin{array}{c}\text { Double } \\
\text { Carbon Share } \\
\left(\theta_{Y C}=0.209\right) \\
(3)\end{array}$ & $\begin{array}{c}\text { Double Sulfur } \\
\text { \& Carbon } \\
\text { Shares } \\
(4)\end{array}$ \\
\hline \multicolumn{6}{|c|}{ Panel A: Tax-Tax Scenario } \\
\hline$\hat{Y}$ & -0.27 & -0.27 & -0.53 & -0.53 \\
$\hat{C}_{Y}$ & -4.59 & -4.44 & -4.34 & -4.18 \\
$\hat{S}$ & -0.90 & -0.90 & -1.79 & -1.79 \\
\hline$\hat{Y}$ & Panel B: Tax-Permit Scenario [Match Tax] \\
\hline$\hat{C}$ & -0.26 & -0.25 & -0.51 & -0.49 \\
$\hat{S}$ & -4.56 & -4.38 & -4.26 & -4.02 \\
\hline
\end{tabular}

Note: Grey cells indicate exogenously set variable. Each cell is independently rounded.

Table 6 column (3) doubles the primary-case carbon price and the carbon share. Intuitively, when the share of carbon is larger, the same $10 \%$ tax increase leads to greater percentage changes in output price and quantity. Mechanically, $\theta_{Y C}$ appears in

\footnotetext{
${ }^{31}$ We use emissions data to calculate the sulfur and carbon shares, while $1=\theta_{Y L}+\theta_{Y C}+\theta_{Y S}$ identifies the labor share as a residual. The literature and U.S. EPA data provide the cross-price Allen-elasticities $\left(e_{L S}, e_{L C}, e_{S C}\right)$. Yet a profit maximizing firm conforms to $a_{i L}+a_{i C}+a_{i S}=0$, where $a_{i j}=\theta_{Y j} e_{i j}$. Thus, the own-price Allen-elasticities are residuals. For example, $e_{S S}=\left(-1 / \theta_{Y S}\right)\left(\theta_{Y C} e_{S C}+\theta_{Y L} e_{L S}\right)$. A consequence is that our small $\theta_{Y S}$ implies large $e_{S S}$. Doubling $\theta_{Y S}$ yields a more reasonable $e_{S S}$.
} 
the numerator of all the closed-form expressions. ${ }^{32}$ Finally, Table 6 column (4) doubles both the sulfur and carbon shares. These results combine the greater differences from column (2) with the greater magnitudes in column (3) to get numerical results that have larger absolute differences than any of the other three columns.

\section{Conclusion}

In order to solve analytically for all price and quantity outcomes in general equilibrium, this paper builds a two-sector model of a closed economy using standard assumptions of perfect competition, constant returns to scale, mobile factors of production, and perfect certainty. Yet we consider two pollutants in the covered sector that may be complements or substitutes, where either pollutant maybe controlled by a tax or by a permit system. We find closed-form solutions that show general equilibrium outcomes for any parameter values, and we provide intuition for our results.

The paper highlights two important ways that pollution taxes and permit policies are not equivalent. First, the quantity change for a pollutant subject to a tax increase depends on whether the other pollutant faces a tax or permit policy. Second, if that other pollutant pays a tax, then general equilibrium effects can increase or decrease its quantity and impact overall welfare. However, when the second pollutant is subject to a permit policy, and that policy binds, then welfare does not change via spillover effects.

The model is general enough that it can be applied to many multiple pollutant problems within and across media. As an example, we conduct a numerical analysis of the U.S. electricity sector that emits carbon dioxide and sulfur dioxide from burning coal. Our most plausible parameters reflect the U.S. EPA assumption that $\mathrm{CO}_{2}$ and $\mathrm{SO}_{2}$ are complements across the entire sector, and so a tax on $\mathrm{CO}_{2}$ increases welfare by reducing both pollutants within the covered sector. The numerical exercise helps demonstrate the two ways that environmental taxes and permits differ in a general equilibrium model with multiple pollutants and initially suboptimal policies.

\footnotetext{
32 Despite these larger differences between columns (1) and (3), the differences within column (3) between the tax-tax scenario and the tax-permit scenario are similar to the difference within column (1).
} 


\section{Appendix A: Factor Demand Responses in Sector $Y$}

Here, we derive equations (7) and (8), describing the input demand responses to changes in input prices. Define the input demand functions from cost minimization:

$$
\begin{aligned}
& L_{Y}=L_{Y}\left(p_{L}, p_{C Y}, p_{S}, Y\right) \\
& C_{Y}=C_{Y}\left(p_{L}, p_{C Y}, p_{S}, Y\right) \\
& S=S\left(p_{L}, p_{C Y}, p_{S}, Y\right) .
\end{aligned}
$$

Next, totally differentiate each input demand function.

$$
\begin{aligned}
& d L_{Y}=\frac{\partial L_{Y}}{\partial p_{L}} d p_{L}+\frac{\partial L_{Y}}{\partial p_{C Y}} d p_{C Y}+\frac{\partial L_{Y}}{\partial p_{S}} d p_{S}+\frac{\partial L_{Y}}{\partial Y} d Y \\
& d C_{Y}=\frac{\partial C_{Y}}{\partial p_{L}} d p_{L}+\frac{\partial C_{Y}}{\partial p_{C Y}} d p_{C Y}+\frac{\partial C_{Y}}{\partial p_{S}} d p_{S}+\frac{\partial C_{Y}}{\partial Y} d Y \\
& d S=\frac{\partial S}{\partial p_{L}} d p_{L}+\frac{\partial S}{\partial p_{C Y}} d p_{C Y}+\frac{\partial S}{\partial p_{S}} d p_{S}+\frac{\partial S}{\partial Y} d Y
\end{aligned}
$$

Divide through each equation by $L_{Y}, C_{Y}$, and $S$, respectively, and rearrange.

$$
\begin{aligned}
& \frac{d L_{Y}}{L_{Y}}=\frac{\partial L_{Y}}{\partial p_{L}} \frac{p_{L}}{L_{Y}} \frac{d p_{L}}{p_{L}}+\frac{\partial L_{Y}}{\partial p_{C Y}} \frac{p_{C Y}}{L_{Y}} \frac{d p_{C Y}}{p_{C Y}}+\frac{\partial L_{Y}}{\partial p_{S}} \frac{p_{S}}{L_{Y}} \frac{d p_{S}}{p_{S}}+\frac{\partial L_{Y}}{\partial Y} \frac{Y}{L_{Y}} \frac{d Y}{Y} \\
& \frac{d C_{Y}}{C_{Y}}=\frac{\partial C_{Y}}{\partial p_{L}} \frac{p_{L}}{C_{Y}} \frac{d p_{L}}{p_{L}}+\frac{\partial C_{Y}}{\partial p_{C Y}} \frac{p_{C Y}}{C_{Y}} \frac{d p_{C Y}}{p_{C Y}}+\frac{\partial C_{Y}}{\partial p_{S}} \frac{p_{S}}{C_{Y}} \frac{d p_{S}}{p_{S}}+\frac{\partial C_{Y}}{\partial Y} \frac{Y}{C_{Y}} \frac{d Y}{Y} \\
& \frac{d S}{S}=\frac{\partial S}{\partial p_{L}} \frac{p_{L}}{S} \frac{d p_{L}}{p_{L}}+\frac{\partial S}{\partial p_{C Y}} \frac{p_{C Y}}{S} \frac{d p_{C Y}}{p_{C Y}}+\frac{\partial S}{\partial p_{S}} \frac{p_{S}}{S} \frac{d p_{S}}{p_{S}}+\frac{\partial S}{\partial Y} \frac{Y}{S} \frac{d Y}{Y}
\end{aligned}
$$

Constant returns to scale production implies that the input demand functions are homogenous of degree one in $Y$, so $\frac{\partial L_{Y}}{\partial Y} \frac{Y}{L_{Y}}=1, \frac{\partial C_{Y}}{\partial Y} \frac{Y}{C_{Y}}=1$, and $\frac{\partial S}{\partial Y} \frac{Y}{S}=1$. Next, the equations can be rewritten using the "hat" notation as:

$$
\begin{aligned}
& \hat{L}_{Y}=a_{L L} \hat{p}_{L}+a_{L C} \hat{p}_{C Y}+a_{L S} \hat{p}_{S}+\hat{Y} \\
& \hat{C}_{Y}=a_{C L} \hat{p}_{L}+a_{C C} \hat{p}_{C Y}+a_{C S} \hat{p}_{S}+\hat{Y} \\
& \hat{S}=a_{S L} \hat{p}_{L}+a_{S C} \hat{p}_{C Y}+a_{S S} \hat{p}_{S}+\hat{Y}
\end{aligned}
$$

where $a_{i j}$ is the elasticity of demand for input $i$ with respect to input price $j$, leaving all the other inputs constant. Using the algebraic identity $a_{i j}=\theta_{Y j} e_{i j}$, then: 


$$
\begin{aligned}
& \hat{L}_{Y}=e_{L L} \theta_{Y L} \hat{p}_{L}+e_{L C} \theta_{Y C} \hat{p}_{C Y}+e_{L S} \theta_{Y S} \hat{p}_{S}+\hat{Y} \\
& \hat{C}_{Y}=e_{C L} \theta_{Y L} \hat{p}_{L}+e_{C C} \theta_{Y C} \hat{p}_{C Y}+e_{C S} \theta_{Y S} \hat{p}_{S}+\hat{Y} \\
& \hat{S}=e_{S L} \theta_{Y L} \hat{p}_{L}+e_{S C} \theta_{Y C} \hat{p}_{C Y}+e_{S S} \theta_{Y S} \hat{p}_{S}+\hat{Y} .
\end{aligned}
$$

Finally, because these equations are not independent, subtract the third from the first and second, respectively, to eliminate $\hat{Y}$, and rearrange using the symmetry of the Allen-elasticities $\left(e_{i j}=e_{j i}\right)$ to yield equations (7) and (8).

\section{Appendix B: Derivation of the Welfare Equation}

Totally differentiate the utility function:

$$
d U=\frac{\partial U}{\partial X} d X+\frac{\partial U}{\partial Y} d Y+\frac{\partial U}{\partial C} d C+\frac{\partial U}{\partial S} d S
$$

Substitute in the first-order conditions (FOCs), $\frac{\partial U}{\partial X}=\lambda p_{X}$ and $\frac{\partial U}{\partial Y}=\lambda p_{Y}$ from the household maximization problem, where $\lambda$ is the Lagrange multiplier on the budget constraint. Next, totally differentiate the production functions for $X$ and $Y$ and substitute the resulting $d X$ and $d Y$ into the equation above to get:

$$
\begin{aligned}
d U & =\lambda p_{X}\left(\frac{\partial X}{\partial L_{X}} d L_{X}+\frac{\partial X}{\partial C_{X}} d C_{X}\right) \\
& +\lambda p_{Y}\left(\frac{\partial Y}{\partial L_{Y}} d L_{Y}+\frac{\partial Y}{\partial C_{Y}} d C_{Y}+\frac{\partial Y}{\partial S} d S\right)+\frac{\partial U}{\partial C} d C+\frac{\partial U}{\partial S} d S
\end{aligned} .
$$

Continuing, totally differentiate the resource constraint using $d L_{X}=-d L_{Y}$ :

$$
\begin{aligned}
d U= & \lambda p_{X}\left[\frac{\partial X}{\partial L_{X}}\left(-d L_{Y}\right)+\frac{\partial X}{\partial C_{X}} d C_{X}\right] \\
& +\lambda p_{Y}\left(\frac{\partial Y}{\partial L_{Y}} d L_{Y}+\frac{\partial Y}{\partial C_{Y}} d C_{Y}+\frac{\partial Y}{\partial S} d S\right)+\frac{\partial U}{\partial C} d C+\frac{\partial U}{\partial S} d S .
\end{aligned}
$$

The profit maximizing FOCs in sector $X$ are $p_{X} \frac{\partial X}{\partial L_{X}}=p_{L}$ and $p_{X} \frac{\partial X}{\partial C_{X}}=p_{C X}$. Also, the FOCs in sector $Y$ are $p_{Y} \frac{\partial Y}{\partial L_{Y}}=p_{L}, p_{Y} \frac{\partial Y}{\partial C_{Y}}=p_{C Y}$, and $p_{Y} \frac{\partial Y}{\partial S}=p_{S}$. Distribute $p_{X}$ and $p_{Y}$ across terms, and substitute the appropriate FOC: 


$$
\begin{aligned}
d U= & -\lambda p_{L} d L_{Y}+\lambda p_{C X} d C_{X} \\
& +\lambda\left(p_{L} d L_{Y}+p_{C Y} d C_{Y}+p_{S} d S\right)+\frac{\partial U}{\partial C} d C+\frac{\partial U}{\partial S} d S .
\end{aligned}
$$

Note that the $p_{L} d L_{Y}$ terms cancel, to leave:

$$
d U=\lambda p_{C X} d C_{X}+\lambda\left(p_{C Y} d C_{Y}+p_{S} d S\right)+\frac{\partial U}{\partial C} d C+\frac{\partial U}{\partial S} d S
$$

Next, divide through by $\lambda$, and substitute the expressions $d C=d C_{X}+d C_{Y}$, $\mu_{C} \equiv-(\partial U / \partial C) / \lambda$, and $\mu_{S} \equiv-(\partial U / \partial S) / \lambda$ into the previous equation to yield:

$$
\frac{d U}{\lambda}=p_{C X} d C_{X}+p_{C Y} d C_{Y}+p_{S} d S-\mu_{C}\left(d C_{X}+d C_{Y}\right)-\mu_{S} d S
$$

where $\mu_{C}$ and $\mu_{s}$ are the marginal environmental damages from carbon and sulfur.

Next, divide through by total income $I$, and employ the "hat" notation, to get the welfare equation in the text.

\section{Appendix C: Carbon and Sulfur Substitution Elasticity}

The EPA's examination of the American Clean Energy and Security Act of 2009 (HR $2454,111^{\text {th }}$ Congress) uses many assumptions in a large complicated model to provide a long-run projection of future emission quantities and prices for both $\mathrm{CO}_{2}$ and $\mathrm{SO}_{2}$. Our Table A-1 reports the emission price-quantity pairs from the EPA's analysis of HR 2454, where panel A is the projected business-as-usual scenario, and panel B makes projections for a simplified version of the proposed cap-and-trade legislation. ${ }^{33}$ We run a simple regression to "estimate” $e_{S C}$, using these price and quantity projections as if they were data. This regression is not based on any observed behavior in response to price changes; it is only meant to summarize all of the EPA assumptions in the form of our single $e_{S C}$ parameter. To proceed, integrate the definition of $e_{S C}$ to obtain:

$$
\log \left(\frac{S}{C_{Y}}\right)=\log (c)-e_{S C} \log \left(\frac{p_{S}}{p_{C Y}}\right)
$$

where $\log (c)$ is the constant of integration. The definition of $e_{S C}$ holds output constant, and therefore we control for output when we linearly regress this equation

\footnotetext{
${ }^{33}$ See http://www.epa.gov/climatechange/economics/economicanalyses.html for this EPA analysis.
} 
using the data in Table A-1 panel B. We find a value for $e_{S C}$ equal to -0.6; that is, the EPA must be assuming, in effect, that the two pollutants are complements. ${ }^{34}$

We also need the cross-price elasticities relating the composite clean input $\left(L_{Y}\right)$ to each pollutant $\left(C_{Y}\right.$ and $\left.S\right)$. Considine and Larson (2006) find 0.47 for the long-run Morishima-elasticity of substitution between labor and sulfur $\left(m_{L S}\right) .{ }^{35}$ Assuming for the moment that $e_{L C}=e_{L S}$, the theorem below shows that the cross-price Allenelasticity $e_{L S}$ also equals $m_{L S}$. Since that was estimated to be 0.47 , we use the rounded value of 0.5 for both $e_{L C}$ and $e_{L S}$ for our numerical example in the text.

Table A-1: U.S. EPA's Projected Input-Output and Quantity-Price Pairs for SO2 and CO2 Emissions, for Electricity Generating Sector (2006 Dollars)

\begin{tabular}{|c|c|c|c|c|c|c|}
\hline Year & $\begin{array}{c}\text { Total } \\
\text { Generation } \\
\text { Cost } \\
\text { (\$billions) }\end{array}$ & $\begin{array}{c}\text { Total } \\
\text { Electricity } \\
\text { Output } \\
\text { (TWh) }\end{array}$ & $\begin{array}{c}\mathrm{SO}_{2} \\
\text { Quantity } \\
\text { (Mtons) }\end{array}$ & $\begin{array}{c}\mathrm{SO}_{2} \\
\text { Price } \\
\text { (\$/ton) }\end{array}$ & $\begin{array}{c}\mathrm{CO}_{2} \\
\text { Quantity } \\
\text { (MMtons) }\end{array}$ & $\begin{array}{c}\mathrm{CO}_{2} \\
\text { Price } \\
(\$ / \text { metric } \\
\text { ton })\end{array}$ \\
\hline \multicolumn{7}{|c|}{ Panel A: Business-As-Usual } \\
\hline 2012 & 123.8 & 4096 & 4277 & 283 & 2362 & - \\
\hline 2015 & 131.5 & 4142 & 4005 & 255 & 2359 & - \\
\hline 2020 & 150.9 & 4352 & 3833 & 308 & 2462 & - \\
\hline 2025 & 165.7 & 4578 & 3691 & 415 & 2566 & - \\
\hline \multicolumn{7}{|c|}{ Panel B: HR 2454} \\
\hline 2012 & 120.7 & 4056 & 4627 & 130 & 2272 & 11.34 \\
\hline 2015 & 121.1 & 3966 & 4119 & 117 & 2164 & 13.14 \\
\hline 2020 & 126.5 & 3930 & 3818 & 142 & 2065 & 16.95 \\
\hline 2025 & 138.1 & 4044 & 3523 & 191 & 2008 & 21.59 \\
\hline
\end{tabular}

(Note: The EPA's analysis only reports values for the four years included in the table. The sulfur dioxide quantity-price pairs come from the national Acid Rain Program's cap-and-trade regime. TWh is a terawatt-hour or $10^{\wedge} 12$ watt-hours, a unit of energy.)

Theorem: Let $Y(i, j, k)$ be a CRTS production function of three inputs for a profit maximizing firm, let $m_{i j}$ denote the cross-price Morishima-elasticity for input $i$ and

\footnotetext{
${ }^{34}$ The standard errors from this regression are misleadingly low, because the EPA's modeling and projections are deterministic. Our procedure here does not yield any statistical properties; it only summarizes the EPA's assumptions about the many unknown parameters and the chosen model structure. The actual "estimate" of the elasticity is approximately -0.62, but we simply use -0.6 to avoid unwarranted claims of accuracy in this estimation.

${ }^{35}$ Blackory and Roberts (1989) can be used to show that the Morishima-elasticity of substitution for quantity $i$ and price $j, m_{i j}$, is related to the Allen-elasticity of substitution by the algebraic identity $m_{i j}=\theta_{Y i}\left(e_{j i}-e_{i i}\right)$.
} 
price $j$, and let $e_{i j}$ denote the cross-price Allen-elasticity for quantity $i$ and price $j$. If $e_{i j}=e_{i k}$, then $m_{i j}=e_{i j}$.

Proof: Blackorby and Roberts (1989) show that $m_{i j}=a_{j i}-a_{i i}$, where $a_{i j}$ is the partial elasticity of substitution in production, and where $a_{i j}=\theta_{Y j} e_{i j}$. Recall that $e_{i j}=e_{j i}$

, and that $\theta_{Y j}$ is the factor share of income for input $j$ in the production of good $Y$, so $\theta_{Y i}+\theta_{Y j}+\theta_{Y k}=1$. Also, the condition $a_{i i}+a_{i j}+a_{i k}=0$ is a property of the profit maximizing firm's optimum, and thus $\theta_{Y i} e_{i i}+\theta_{Y j} e_{i j}+\theta_{Y k} e_{i k}=0$. Under our assumption $e_{i j}=e_{i k}$, it holds that $\left(\theta_{Y j}+\theta_{Y k}\right) e_{i j}=-\theta_{Y i} e_{i i}$, and:

$$
\begin{aligned}
m_{i j} & =a_{j i}-a_{i i} \\
& =\theta_{Y i} e_{j i}-\theta_{Y i} e_{i i} \\
& =\theta_{Y i} e_{i j}-\theta_{Y i} e_{i i} \\
& =\theta_{Y i} e_{i j}+\left(\theta_{Y j}+\theta_{Y k}\right) e_{i j} \\
& =e_{i j}
\end{aligned}
$$

\section{References}

Agee, Mark D., Scott E. Atkinson, Thomas D. Crocker, and Jonathan W. Williams (2014), “Non-separable Pollution Control: Implications for a $\mathrm{CO}_{2}$ Emissions Cap and Trade System,” Resource and Energy Economics, 36(1), 64-82.

Allen, Roy. G. D. (1938): Mathematical Analysis for Economists. St. Martin's Press, New York.

Ambec, Stefan, and Jessica Coria (2013): "Prices vs. Quantities with Multiple Pollutants,” Journal of Environmental Economics and Management, 66(1), 123-40.

Baylis, Kathy, Don Fullerton, and Daniel H. Karney (2014): "Negative Leakage," Journal of the Association of Environmental and Resource Economists, 1(1), 51-73.

Blackorby, Charles, and R. Robert Russell (1989): "Will the Real Elasticity of Substitution Please Stand Up? (A Comparison of the Allen/Uzawa and Morishima Elasticities,” American Economic Review, 84(4), 1085-89.

Bovenberg, A. Lans, and Ruud A. de Mooij (1994): "Environmental Levies and Distortionary Taxation,” American Economic Review , 84(4), 1085-9.

Burtraw, Dallas, Alan Krupnick, Erin Mansur, David Austin, and Deirdre Farrell (1998): "Costs and Benefits of Reducing Air Pollutants Related to Acid Rain," Contemporary Economic Policy, 16(4), 379-400. 
Burtraw, Dallas, Alan Krupnick, Karen Palmer, Anthony Paul, Michael Toman, and Cary Bloyd (2003): “Ancillary Benefits of Reduced Air Pollution in the US from Moderate Greenhouse Gas Mitigation Policies in the Electricity Sector,” Journal of Environmental Economics and Management, 45(3), 650-73.

Carlson, Curtis, Dallas Burtraw, Maureen Cropper, and Karen L. Palmer (2000): "Sulfur Dioxide Control by Electric Utilities: What Are the Gains from Trade?," Journal of Political Economy, 16(4), 379-400.

Considine, Timothy J., and Donald F. Larson (2006): “The Environment as a Factor of Production,” Journal of Environmental Economics and Management, 52(3), 64562.

Färe, Rolf, Shawna Grosskopf, Carl A. Pasurka Jr., and William L. Weber (2012): "Substitutability among Undesirable Outputs,” Applied Economics, 44, 39-47.

Fullerton, Don, and Garth Heutel (2007): “The General Equilibrium Incidence of Environmental Taxes,” Journal of Public Economics, 91(3-4), 571-91.

Fullerton, Don, and Garth Heutel (2010): “The General Equilibrium Incidence of Environmental Mandates,” American Economic Journal: Economic Policy, 2(3), 64-89.

Fullerton, Don, and Gilbert Metcalf (2001): "Environmental Controls, Scarcity Rents, and Pre-existing Distortions,” Journal of Public Economics, 80(2), 249-67.

Gamper-Rabindran, Shanti (2006): “Did the EPA's Voluntary Industrial Toxics Program Reduce Emissions? A GIS Analysis of Distributional Impacts and Bymedia Analysis of Substitution,” Journal of Environmental Economics and Management, 52(1), 391-410.

Greenstone, Michael (2003), "Estimating Regulation-Induced Substitution: The Effect of the Clean Air Act on Water and Ground Pollution," American Economic Review Papers and Proceedings, 93(2), 442-448.

Groosman, Britt, Nicholas Z. Muller, and Erin O’Neill (2011): “The Ancillary Benefits from Climate Policy in the United States," Environmental and Resource Economics, 50(4), 585-603.

Hassett, Kevin, Aparna Mathur, and Gilbert Metcalf (2009): "The Incidence of a U.S. Carbon Tax: A Lifetime and Regional Analysis,” Energy Journal, 30(2), 155-77.

Holland, Stephen P. (2012a): “Emissions Taxes and versus Intensity Standards: SecondBest Environmental Policies with Incomplete Regulation," Journal of Environmental Economics and Management, 63(3), 375-387

Holland, Stephen P. (2012b): "Spillovers from Climate Policy," in The Design of Implementation of Climate Policy, Don Fullerton and Catherine Wolfram, editors, University of Chicago Press.

Karp, Larry (2013): “The Income and Production Effects of Leakage,” Working paper, University of California, Berkeley, CA.

Kolstad, Charles et al. (2014): "Social, Economic and Ethical Concepts and Measurement”, in Climate Change 2014: Mitigation of Climate Change, Intergovernmental Panel on Climate Change (IPCC), Fifth Assessment Report (WGIII). 
Metcalf, Gilbert, and David Weisbach (2009): “The Design of a Carbon Tax,” Harvard Environmental Law Review, 33(2), 499-556.

Mieszkowski, Peter (1972): “The Property Tax: An Excise Tax or a Profits Tax?,” The Journal of Public Economics, 1(1), 73-96.

Moslener, Ulf, and Till Requate (2007), “Optimal Abatement in Dynamic Multipollutant Problems When Pollutants Can Be Complements or Substitutes,” Journal of Economic Dynamics and Control, 31(7), 2293-316.

Muller, Nicholas Z. (2014): "Using Index Numbers for Deflation in Environmental Accounting,” Environment and Development Economics, 19(4), 466-86.

Muller, Nicholas Z., and Robert Mendelsohn (2009): "Efficient Pollution Regulation: Getting the Right Prices,” American Economic Review, 99(5), 1714-39.

Ren, Xiaolin, Don Fullerton, and John B. Braden (2011): “Optimal Taxation of Externalities Interacting through Markets: A Theoretical General Equilibrium Analysis,” Resources and Energy Economics, 33(3), 496-514.

Ross, Martin T. (2008): "Documentation of the Applied Dynamic Analysis of the Global Economy (ADAGE) Model,” Research Triangle Institute Working Paper 08_01 Durham NC (http://www.rti.org/pubs/adage-model-doc_ross_sep08.pdf).

Schmalensee, Richard, Paul L. Joskow, A. Denny Ellerman, Juan Pablo Montero, and Elizabeth M. Baily (1998): “An Interim Evaluation of Sulfur Dioxide Emissions Trading,” Journal of Economic Perspectives, 12(3), 53-68.

Sigman, Hilary (1996), "Cross-Media Pollution: Responses to Restrictions on Chlorinated Solvent Releases” Land Economics, 72(3), 298-312.

Tol, Richard S. J. (2009): “The Economic Effects of Climate Change,” Journal of Economic Perspectives, 23(2), 29-51.

U.S. BEA (2009): “National Income and Product Accounts Tables: 1.5.5. GDP”, (link: http://www.bea.gov/national/nipaweb/SelectTable.asp?Selected=N), Washington, DC.

U.S. EIA (2009): “Electric Power Monthly: July 2009 [Table 5.2]”, (link: http://www.eia.gov/electricity/monthly/archive/pdf/02260907.pdf), Washington, DC.

U.S EPA (accessed 2009a): “2009 U.S. Greenhouse Gas Inventory Report”, Table ES2: Recent Trends in U.S. Greenhouse Gas Emissions and Sinks, (link: http://www.epa.gov/climatechange/emissions/usinventoryreport09.html), Washington, DC.

U.S. EPA (accessed 2009b): "National Emissions Inventory (NEI) Air Pollution Emissions Trend Data”, Sulfur Dioxide Annual Data, (link: http://www.epa.gov/ttn/chief/trends/), Washington, DC.

Weitzman, Martin L. (1974): “Prices vs. Quantities,” The Review of Economic Studies, 41(4), 477-91. 